\title{
La distribución funcional de la renta en España entre 1914 y 1959: una propuesta de análisis
}

\author{
Functional Distribution of Income in Spain (1914-1959): \\ a proposal of analysis \\ MARGARITA VILAR RODRÍGUEZ \\ Universidad de A Coruña
}

\begin{abstract}
RESUMEN
El análisis de la distribución funcional del ingreso en España desde una perspectiva histórica ha sido un tema muy espinoso para la historiografía debido a las graves deficiencias estadísticas. El principal objetivo de este trabajo es ofrecer una nueva herramienta cuantitativa con la que poder contrastar empíricamente los argumentos sostenidos hasta el momento con escaso apoyo estadístico. El indicador propuesto se define como la ratio entre los ingresos de los trabajadores industriales y los beneficios empresariales en España entre 1914 y 1959. Su evolución a largo plazo ha permitido establecer, en primer lugar, algunos matices interesantes sobre las pautas distributivas en la economía española antes y después de la Guerra Civil. En segundo lugar, la evidencia cuantitativa obtenida revela que en la posguerra la baraja se decantó claramente a favor de los ingresos del capital frente a los del trabajo asalariado, rompiendo con la tendencia vigente en el período prebélico.
\end{abstract}

PALABRAS CLAVE: Distribución Renta, Salarios, Beneficios, Economía Española, Franquismo, Siglo XX

Códigos JEL: N34, N44, D33

\begin{abstract}
The analysis of the functional distribution of income in Spain from a historical perspective has created many obstacles to historiography due to the lack of statistical sources. The main objective of this research is to offer a new quantitative tool which lets empirically test many arguments sustained in this field - with little statistical support- until this moment. The proposed indicator is defined as the ratio between the income corresponding to the industrial workers and the enterprise profits in Spain from 1914 to 1959. Its long-term behaviour identifies, firstly, some interesting trends on the distributive guidelines in the Spanish economy before and after the Civil War. Secondly, the quantitative evidence reveals that the capital income was clearly favoured in the post-War period at the same time as the labour income was clearly damaged. As a consequence, the prevailing distributive pattern in this economy over the course of the pre-War decades was modified.
\end{abstract}

KEY WORDS: Income Distribution, Wages, Profits, Spanish Economy, Francoism, 20 ${ }^{\text {th }}$ Century JEL Codes: N34, N44, D33 


\section{Introducción ${ }^{1}$}

$\mathrm{H}$

ace ya casi una década $X$. Tafunell planteaba la paradoja de que, aunque los grandes avatares de la historia contemporánea de España han estado ligados a cambios en la distribución de la renta, no contamos con series históricas de la participación de los diferentes factores productivos en el ingreso nacional ${ }^{2}$. Una rápida revisión de la historiografía española nos permite constatar esta idea. En efecto, las variaciones en el reparto de la renta han estado presentes -implícita o explícitamente - como elementos de apoyo a la hora de argumentar los avances y retrocesos de la economía española entre 1914 y 1959, a pesar de la falta de estadísticas "suficientes y creíbles" 3 . En particular, desde un punto de vista macro, es posible destacar graves deficiencias cuantitativas que afectan a las tres principales fuentes de ingresos (propiedad, capital y trabajo).

En primer lugar, hay que recordar que el conocimiento de las rentas de la propiedad en España es muy tardío. En el caso de la propiedad rural, el Catastro de la Riqueza Rústica comenzó a elaborarse en 1906, pero no se finalizó hasta 19594. Algo similar ocurre con las rentas de la propiedad urbana que constituyen todavía un terreno por explorar ${ }^{5}$. La utilización de fuentes de carácter fiscal podría ayudar a cubrir parte de estas lagunas. Sin embargo, algunos autores opinan que el desprestigio general de las fuentes fiscales españolas entre los historiadores económicos es tan grande que desaconseja su utilización para el análisis histórico ${ }^{6}$.

En cuanto a los ingresos empresariales, muy pocas sociedades españolas publicaron regularmente memorias con sus estados financieros anuales hasta la segunda mitad del siglo XX. El principal problema reside en que, hasta una fecha tan tardía como la década de 1970, las sociedades mercantiles carecieron de un marco normativo adecuado para la confección de una cuenta de resultados pública y veraz ${ }^{7}$.

Por último, respecto a los salarios, el déficit estadístico ha sido muy importante durante la primera mitad del siglo $X^{8}$. En este terreno, a la escasez y poca fiabilidad de las fuentes estadísticas salariales disponibles, hay que añadir las característi-

[Fecha de recepción del original, febrero de 2005. Versión definitiva, mayo de 2006]

${ }^{1}$ Agradezco los comentarios que los evaluadores anónimos de Investigaciones de Historia Económica han realizado a la versión del texto inicialmente presentada. Mi agradecimiento también a Xavier Tafunell y Daniel A. Tirado por su estímulo para que realizara este trabajo y por sus sugerentes observaciones para mejorarlo. Obviamente, los errores o deficiencias que puedan persistir son de mi absoluta responsabilidad.

2 Tafunell (1998), p. 708.

${ }^{3}$ Tafunell (1998), p. 708.

${ }^{4}$ Además, los primeros datos catastrales presentan altos niveles de ocultación de la riqueza rústica a la vez que una elevada tendencia a clasificar los terrenos en categoría fiscales inferiores o, directamente, como yermos e improductivos. Véanse Comín (1988), p. 930; y Pro (1995), p. 90.

${ }^{5}$ Maluquer (1989), pp. 26-27.

${ }^{6}$ Betrán (1994), p. 312; Catalan (1995), p. 126; y Comín (1996), pp. 94-115.

7 Tafunell (1998), p. 717.

${ }^{8}$ Un análisis crítico de las fuentes salariales disponibles en España entre 1908 y 1963 en Vilar (2004b). 
cas tan diferentes del marco salarial vigente en España antes y después de la Guerra Civil. Esta disparidad añade dificultades a la hora de construir una serie continua sobre el comportamiento de los salarios que ofrezca ciertas garantías de homogeneidad 9 .

Sin embargo, en los últimos años, la elaboración de dos series históricas sobre la evolución de los beneficios empresariales ${ }^{10}$ y los salarios industriales ${ }^{11}$ ha permitido cubrir una parte importante de este vacío estadístico. La disponibilidad de esta evidencia cuantitativa, aunque insuficiente para abordar el análisis global de la distribución funcional del ingreso en España, permite avanzar en esta dirección desde una perspectiva de largo plazo. No obstante, es necesario recordar que ninguna de estas dos series está exenta de importantes limitaciones ${ }^{12}$. Entre otras muchas, podemos destacar que la estimación de beneficios sólo es representativa de la gran empresa española con régimen jurídico de sociedad anónima, y que la serie de salarios se refiere únicamente a la mano de obra masculina en la industria.

No cabe duda de que considerar sólo las empresas de gran tamaño puede introducir un importante sesgo en el comportamiento de los beneficios en el largo plazo. Sobre todo si se tiene en cuenta que, antes de la Guerra Civil, el tamaño medio de las empresas en España era bastante reducido. Por lo general, en este período, solían predominar los talleres sobre las fábricas y las formas artesanales eran aún abundantes en la organización productiva ${ }^{13}$. Además, los grandes grupos empresariales disfrutan por lo general de una mayor capacidad de influencia en los círculos de poder $y$, en determinadas coyunturas políticas, este efecto puede influir en sus cuentas de resultados ${ }^{14}$. Por otro lado, al contabilizar únicamente aquellas empresas con forma jurídica de sociedad anónima, la estructura sectorial de la industria puede resultar distorsionada, especialmente en el lapso anterior a la Guerra Civil. Como consecuencia, los beneficios empresariales podrían verse afectados, aunque no es posible evaluar hasta qué punto ${ }^{15}$.

Las limitaciones que presenta la serie histórica de salarios requieren también algunos comentarios. En primer lugar, la utilización de los salarios industriales supone dejar fuera del análisis a la agricultura y a los servicios. Respecto a este último sector, el vacío estadístico sigue siendo una barrera a franquear por la historiografía

\footnotetext{
${ }^{9}$ Sobre este aspecto, véase Vilar (2004a), cap. 2.

${ }^{10} \mathrm{El}$ origen de los datos y la metodología utilizada para elaborar la serie de beneficios puede verse en Tafunell (1998). Conviene recordar al lector que esta estimación de beneficios hace referencia al concepto contable de «resultado económico bruto total», es decir, el resultado neto total más las dotaciones para amortizaciones y provisiones. Esta categoría económico-contable no coincide exactamente, ni con el excedente bruto de explotación que utiliza la Contabilidad Nacional, ni con el beneficio neto que calcula el Servicio de Estudios del Banco de Bilbao.

${ }^{11}$ El origen de los datos y la metodología utilizada para elaborar la serie de salarios, en Vilar (2004b).

12 En Tafunell (1998) y Vilar (2004b) se analizan las principales deficiencias que presentan ambas series.

${ }_{13}$ Soto (1989), p. 67.

${ }^{14}$ Catalan (1995), p. 125.

${ }^{15}$ Aubanell (1994), p. 163.
} 
española. En el caso de la agricultura, los problemas son de diferente orden. En particular, una parte de la literatura ha cuestionado la validez de las series de salarios agrícolas para representar los ingresos de los trabajadores pertenecientes a este sector $^{16}$. La razón de fondo descansa en las propias características del sector, en el que, con frecuencia, nos encontramos con pagos en metálico y en especie, trabajo a destajo, remuneraciones dispares según el tipo de cultivo y la época del año, estacionalidad en el trabajo y altos niveles de autoconsumo. Además, el grado de colaboración de todos los miembros de la familia en las tareas agrícolas suele ser muy elevado. Considerando esta circunstancia, algunos autores opinan que para la agricultura resultaría más adecuado el cálculo de un «salario familiar» ${ }^{17}$. Por estas y otras razones, a la hora de estimar los ingresos de las familias campesinas se considera más fructífera la aproximación microanalítica ${ }^{18}$. No cabe duda de que, por un lado, este enfoque micro ofrece una información más detallada que permite conocer mejor la complejidad de las economías familiares. Por otro, permite superar los problemas de la debilidad de las fuentes oficiales, y aquellos otros derivados de la existencia de diferentes estructuras agrarias a lo largo de la geografía española.

La envergadura de estas limitaciones, cuya resolución exigiría un capítulo aparte, justifica que en este estudio se haya optado por trabajar únicamente con el salario industrial. Esta simplificación, aunque importante, no debe restar interés al análisis. Sólo hay que tener en cuenta que en el sector secundario es donde mejor se reflejan los efectos de los cambios estructurales que acompañan a los procesos de crecimiento. Además, en el transcurso del período objeto de estudio, la industria concentraba a la mayor parte de las grandes empresas, un aspecto que hace más compatibles las series de salarios industriales y de beneficios.

En segundo lugar, tal y como se ha señalado, dentro de los salarios industriales se han dejado al margen a las trabajadoras pertenecientes a este sector ${ }^{19}$. El problema radica en que, históricamente, los salarios de la mano de obra industrial femenina aparecen tan sólo de una manera testimonial en la mayor parte de las fuentes estadísticas de carácter oficial ${ }^{20}$. Esta tradicional discriminación fue reforzada en la posguerra por un marco político y laboral especialmente desfavorable para la mujer ${ }^{21}$. Como consecuencia, todavía no disponemos de una serie histórica continua sobre la evolución de sus ingresos salariales. No obstante, hay que matizar que en este terreno se ha avanzado mucho para el período anterior a la Guerra Civil22. El panorama entraña muchas más dificultades para las décadas posteriores a dicho conflicto,

\footnotetext{
${ }^{16}$ Erdozain (2000) y Sarasúa (2000).

17 Sarasúa (2000), p. 84.

18 Erdozain (2000), p. 62.

${ }_{19}$ Un criterio que introduce una importante limitación en el análisis. Véanse, por ejemplo, Camps (1997), Carrasco y Mayordomo (2000) o la introducción de la obra editada por Sarasúa y Gálvez (2003). ${ }^{20}$ La utilización de fuentes y metodologías alternativas permite "encontrar" a la mujer trabajadora oficialmente “desaparecida”. Véanse Pérez-Fuentes (1995), Arbaiza (2000) y Sarasúa y Gálvez (2003).

${ }^{21}$ Molinero (1998).

22 Sirvan como ejemplo los trabajos de Soto (1989) o Silvestre (2005).
} 
aunque, especialmente desde una perspectiva micro, se está abriendo poco a poco el camino $^{23}$.

Con este telón de fondo, este artículo tiene como objetivo principal abordar el análisis de los cambios en la distribución funcional del ingreso en la economía española entre 1914 y 1959 utilizando nueva evidencia cuantitativa. En particular, este trabajo propone una aproximación al análisis de las pautas distributivas entre el factor capital y el trabajo en la industria española a través de la relación entre la masa salarial y los beneficios empresariales. Obviamente, por las limitaciones que presentan las series disponibles de salarios y beneficios, esta relación no representa al conjunto de las rentas del trabajo y capital, sino sólo a una parte que no ha de ser confundida con el todo. Siendo conscientes de esta circunstancia, no cabe duda de que este indicador nos va a permitir disponer de una nueva herramienta cuantitativa con la que poder superar las deficiencias estadísticas existentes en este terreno.

Ahora bien, dada la escasez de trabajos sobre esta cuestión en la historiografía española, se ha considerado oportuno ofrecer previamente un breve repaso al marco teórico y empírico del estudio de la distribución funcional del ingreso en el marco internacional.

\section{El estudio de la distribución funcional de la renta: un marco teórico y empí- rico}

Desde un punto de vista teórico, la perspectiva desde la que se han estudiado las transformaciones en la distribución funcional del ingreso ha ido cambiando en intensidad y forma según las distintas escuelas de pensamiento. Esta evolución ha transcurrido paralela a las transformaciones que iban teniendo lugar en el seno de las diferentes economías, a medida que éstas alcanzaban un mayor nivel de desarrollo. En este sentido, es posible afirmar que el estudio de la distribución del ingreso, al igual que otros muchos aspectos de la teoría económica, ha estado moldeado por la realidad histórica. Además, con el objetivo de dar una mayor consistencia a sus modelos teóricos, muchos autores han tratado de buscar el apoyo cuantitativo. Sin embargo, esta aproximación sólo fue posible a partir del siglo XX, a medida que se confeccionaban las series históricas de la contabilidad nacional y avanzaban las técnicas estadísticas. No cabe duda de que los análisis empíricos han enriquecido el estudio de la distribución funcional del ingreso en la literatura internacional. Sin embargo, con este enfoque también aparecieron nuevos problemas metodológicos, tal y como comentaremos a lo largo de este epígrafe.

\subsection{El marco teórico de la distribución funcional del ingreso desde una perspectiva histórica}

\footnotetext{
${ }^{23}$ Más comentarios sobre este aspecto en Vilar (2006).
} 
La raíz de este marco teórico se puede situar en los autores de la escuela clásica, quienes dibujaron el boceto inicial. En sus trabajos prestaron atención a la distribución del ingreso entre factores de producción e identificaron fuentes de renta con clases particulares de personas ${ }^{24}$. Su principal objetivo consistía en aclarar cómo cada una de las clases sociales conseguía y se repartía los ingresos. Dentro del "universo clásico" la elevación de la participación de las rentas de los trabajadores no sería efectiva en el largo plazo, pues traería como consecuencia una elevación de la tasa de natalidad entre los obreros, un incremento de la oferta de mano de obra y, consiguientemente, una disminución del salario. Además, de forma análoga, un patrón más igualitario de distribución del ingreso - a favor del factor trabajo - reduciría el ahorro nacional y ralentizaría el crecimiento económico.

Este legado analítico fue importante en la literatura posterior. No obstante, los preceptos clásicos tuvieron que ir amoldándose a las nuevas circunstancias que presentaban unas economías inmersas en procesos de industrialización. Seguramente, el contexto económico que le tocó vivir a Marx condicionó su pensamiento teórico y lo alejó de la doctrina clásica. Sus leyes sobre el movimiento capitalista dibujaban un futuro aciago para el factor trabajo. Por un lado, la búsqueda del beneficio por parte de los capitalistas conduciría a la sustitución del trabajo por el capital, a medida que se pudieran ir incorporando los nuevos avances tecnológicos, con el consiguiente aumento del paro. Por otro lado, el deseo de los propietarios de los medios de producción de mantener su tasa de ganancia constreñiría los salarios. En consecuencia, el proceso capitalista conduciría finalmente a la miseria del proletariado.

Durante el siglo XIX se produjo una reorientación del pensamiento económico dentro del marco de la teoría neoclásica. Esta nueva corriente estaba relacionada con la prosperidad de las economías occidentales y los avances en la teorización económica. En esta etapa los economistas se apoyaron en proposiciones más científicas a la vez que enunciaban conclusiones menos pesimistas sobre el futuro de la economía ${ }^{25}$. Hay que tener en cuenta que los autores de esta generación fueron testigos directos de cómo la presión de las organizaciones obreras en las economías más avanzadas había logrado mejorar las condiciones de trabajo. De forma paralela, la introducción de nuevos cambios técnicos y organizativos exigía mejoras en el nivel de cualificación de la mano de obra. No obstante, también fueron conscientes de que el proceso de modernización económica presentaba problemas serios que exigían ciertos ajustes. Entre los problemas más visibles destacaba, en primer lugar, la enorme diferencia en materia de bienestar entre quienes aportaban su trabajo y quienes suministraban el capital industrial y ejercían la autoridad y, en segundo lugar, el aumento del desempleo. Para afrontar esa situación socialmente indeseable se comenzó a plantear la posibilidad de que el Estado, a través de medidas de política económica, pudiera resolver tales desajustes ${ }^{26}$.

\footnotetext{
${ }^{24}$ Como principales integrantes de esta tradición clásica podemos destacar a Smith (1987 [1776]), Ricardo (1953 [1817]) y Mill (1951 [1848]).

${ }^{25}$ Galbraith (1993), p. 127.

${ }^{26}$ Marshall (1963 [1890]), p. 426; y Barber (1988), p. 184.
} 
En el período de entreguerras, el sistema económico de la mayoría de los países industriales se vio sacudido por una crisis de dimensiones sin precedentes, que vino acompañada de altas tasas de desempleo y descontento social. La tradición neoclásica ortodoxa no estaba preparada para enfrentarse con una situación de estas características, y la mayor parte de los gobiernos occidentales se afanaron en la búsqueda de nuevos enfoques y soluciones ${ }^{27}$. En este contexto, la obra de Keynes ofreció una nueva interpretación teórica del comportamiento del sistema económico.

Entre otros aspectos, este autor mostró interés por la relevancia que habían ido adquiriendo los costes salariales en el ámbito productivo. Para estudiarla, abordó el análisis de la participación de las rentas del trabajo en el ingreso nacional. Sin embargo, al tratar de contrastar empíricamente esta evolución, se encontró con un resultado sorprendente ${ }^{28}$. En efecto, los datos revelaban que, tanto en Gran Bretaña como en Estados Unidos, el porcentaje de la renta nacional que suponían los ingresos salariales se había mantenido estable durante el período de entreguerras, independientemente del nivel de output y del grado de apertura comercial. Sin embargo, Keynes no llegó a explicar las causas que estaban detrás de ese comportamiento.

Los años cincuenta del siglo XX trajeron un soplo de aire fresco en el ámbito de la teoría de la distribución. En este lapso adquirieron protagonismo un grupo de investigadores que otorgaban un amplio apoyo cuantitativo a las ideas keynesianas y que participaron activamente en las políticas aplicadas tras la II Guerra Mundial29. Utilizando nuevas evidencias cuantitativas y traduciendo el pensamiento keynesiano al lenguaje estadístico, trataron de analizar el reparto del ingreso entre los diferentes factores de producción desde una perspectiva histórica ${ }^{30}$. Su principal preocupación se centró en identificar los elementos que estaban detrás de los cambios en la distribución funcional del ingreso dentro de cada país. A diferencia de otras investigaciones precedentes, llegaron a la conclusión de que, al menos desde la I Guerra Mundial, los cambios estructurales implícitos en los procesos de crecimiento de los países tendieron a aumentar la participación de los ingresos salariales en la renta nacional.

Según su argumentación, esta creciente participación vendría impulsada básicamente por dos tendencias compartidas por la mayor parte de economías durante sus respectivos procesos de modernización: de un lado, el aumento de los trabajadores asalariados, a la vez que disminuye el porcentaje de activos agrícolas, aumenta el tamaño de las empresas y se incorporan las mujeres al mercado de trabajo; de otro, la mejora de las condiciones salariales, como consecuencia de la mayor capacidad de negociación de las organizaciones obreras. Todos estos procesos fueron acompañados por un papel cada vez más activo del Estado a través de políticas de carácter redistributivo ${ }^{31}$.

\footnotetext{
${ }^{27}$ Una reflexión sobre estos aspectos en Barber (1988), p. 211.

${ }^{28}$ Keynes (1939), pp. 48-51.

${ }^{29}$ Véase Galbraith (1993), pp. 206 y 267-270.

30 Deninson (1952), Solow (1958), Kuznets (1959) y Kravis (1968).

${ }^{31}$ En este punto es necesario añadir la importancia del aumento de la productividad como factor explicativo del alza secular de los salarios. Sólo hay que recordar que los cambios en la participación de
} 
Ahora bien, estos autores reconocen también que en las economías desarrolladas se fueron produciendo otros cambios que pudieron frenar los avances en la participación relativa de las rentas salariales ${ }^{32}$. Así, por ejemplo, las transformaciones en la estructura interna de la industria favorecieron relativamente más a aquellos sectores menos intensivos en factor trabajo, debido a la introducción de nuevos avances tecnológicos. A este efecto habría que añadir otros relacionados con la reducción del número de horas trabajadas o con el aumento por término medio de la edad de entrada en el mercado laboral.

El marco de análisis acerca de los aspectos distributivos se ha ampliado en las últimas décadas. En particular, la literatura internacional más reciente ha mostrado un especial interés por el análisis de la relación bilateral entre los procesos de crecimiento y la distribución de la renta. La idea de partida de estos trabajos descansa en una doble proposición. Primero, se asume que el crecimiento de la renta está vinculado al modo en cómo ésta se distribuye entre los diferentes factores productivos ${ }^{33}$. Y, segundo, se postula que la modernización económica de un país puede modificar su patrón distributivo ${ }^{34}$. Partiendo de estas dos premisas, los principales desafíos de estos trabajos se centran en averiguar cuáles son los signos de estas relaciones y a través de qué canales se producen estos impactos.

La mayoría de estos estudios se limita a analizar el comportamiento de los ingresos del capital y el trabajo. Esto es debido a que cuando las economías se van modernizando y la renta aumenta, la distribución del ingreso depende cada vez más de la movilización de recursos productivos a través del capital y el trabajo, y no tanto de la distribución de la riqueza acumulada con anterioridad. De forma paralela, apoyándose en la idea de que en las sociedades más desarrolladas y con regímenes democráticos el papel redistributivo del Estado es más fuerte, algunos autores han mostrado un especial interés por analizar hasta qué punto las políticas impositivas y de gasto público han funcionado como mecanismos de redistribución de la renta ${ }^{35}$.

\subsection{Principales problemas del análisis empírico de la distribución funcional del ingre- so}

La literatura internacional que compara la evolución de la distribución del ingreso en diferentes países desde una perspectiva histórica es realmente escasa. Sin embargo, la evidencia cuantitativa disponible ofrece un intenso debate abierto entre economistas e historiadores. Por un lado, estos últimos defienden la existencia de una creciente

\footnotetext{
los ingresos salariales dentro del PIB pueden expresarse como la diferencia entre las variaciones del salario medio y la productividad del trabajo. Como consecuencia, resulta sorprendente que muchos análisis históricos de la distribución funcional de la renta no la hayan tenido en cuenta en sus planteamientos teóricos.

32 Solow (1958), p. 619.

33 Galor y Zeira (1993), Barro (1999) o Bértola (2005), entre otros.

34 Williamson y Lindert (1980), Van Zanden (1995) o Atkinson y Bourguignon (2000).

35 Álvarez, Ayala, Iriondo, Martínez, Palacio y Ruiz-Huerta (1996) y Rodrik (1999).
} 
participación de los ingresos salariales en la renta nacional en los países más avanzados durante el período objeto de estudio ${ }^{36}$. Por otro, los primeros sugieren que un tratamiento más cuidadoso de los datos conduce a la conclusión de que la participación del ingreso se mantuvo aproximadamente constante en los distintos países ${ }^{37}$. Empero, la evidencia histórica refuta la tesis defendida por los economistas (Cuadro 1) ${ }^{38}$.

\section{CUADRO 1}

DISTRIBUCIÓN FUNCIONAL DEL INGRESO EN DIFERENTES PAÍSES

(porcentajes de la Renta Nacional)*

\begin{tabular}{|c|c|c|c|c|c|c|c|}
\hline Reino Unido & Trabajo & Capital & Propiedad & Francia & Trabajo & Capital & Propiedad \\
\hline $1905-1914$ & 47,2 & 16,2 & 36,6 & 1913 & 44,6 & 33,1 & 22,3 \\
\hline $1920-1929$ & 59,7 & 14,6 & 25,7 & $1920-1929$ & 50,4 & 29,1 & 20,5 \\
\hline $1930-1939$ & 62,2 & 13,7 & 24,1 & 1929-1938 & 56,2 & 23,7 & 20,1 \\
\hline $1940-1949$ & 68,8 & 12,9 & 18,3 & $1952-1956$ & 59,1 & 31,3 & 9,6 \\
\hline $1945-1954$ & 71,6 & 12,2 & 16,2 & & & & \\
\hline Estados Unidos & Trabajo & Capital & Propiedad & Alemania & Trabajo & Capital & Propiedad \\
\hline $1915-1924$ & 56,9 & 21,2 & 21,9 & 1913 & 47,8 & 32,7 & 19,5 \\
\hline $1925-1934$ & 64,5 & 15,4 & 20,1 & $1925-1929$ & 64,4 & 26,2 & 9,4 \\
\hline $1934-1943$ & 65,1 & 16,5 & 18,4 & $1930-1934$ & 67,7 & 22,9 & 9,4 \\
\hline $1944-1953$ & 65,6 & 16,4 & 18,0 & $1935-1938$ & 62,9 & 26,7 & 9,4 \\
\hline $1954-1963$ & 69,9 & 11,9 & 18,2 & $1955^{\star *}$ & 63,6 & --- & --- \\
\hline
\end{tabular}

* La muestra de países está condicionada por la escasa evidencia estadística disponible para el período estudiado. Los porcentajes correspondientes a cada uno pueden tener problemas de homogeneidad, pero permiten disponer de una visión general de las tendencias distributivas en el largo plazo.

** Se refiere exclusivamente a la República Federal Alemana.

Fuentes: Kuznets (1959), Kravis (1968) y Prados Arrarte (1972).

En el fondo de este debate hay muchos problemas de carácter metodológico, acompañantes habituales de los trabajos realizados en este ámbito hasta la actualidad. En particular, las dificultades comienzan por la definición y clasificación de algunas fuentes de ingreso, y se agravan por las deficientes estadísticas disponibles. A partir de aquí se abre un amplio abanico de cuestiones muy difíciles de resolver. Por lo que se refiere al trabajo y al capital podemos destacar dos problemas básicos ${ }^{39}$.

En primer lugar, en la literatura no existe un acuerdo general sobre cuál es la definición más adecuada de los términos "trabajador" y "capitalista". Genéricamente, se considera como trabajador a aquel individuo que vive de su salario y como capitalista al que lo hace de sus rentas. Pero esta es una clasificación muy poco realista, pues trabajadores y capitalistas a menudo se confunden. Basta recordar, por ejemplo,

\footnotetext{
${ }^{36}$ Brenner, Kaelble y Thomas (1991), p. 35. Estas conclusiones fueron ratificadas por el informe realizado por la Comisión Económica para Europa de las Naciones Unidas en 1956, reproducido en Prados Arrarte (1972). Este informe revela que en catorce países de Europa occidental esa participación salarial aumentó entre 1938 y 1955.

${ }^{37}$ Gollin (2002), p. 459.

38 Con la excepción del caso alemán entre 1935 y 1955, un comportamiento anómalo que ya ha sido apuntado antes, aunque no analizado con detenimiento, por Brenner, Kaelble y Thomas (1991), p. 35, y Prados y Rosés (2003), p. 6.

${ }^{39}$ Krueger (1999), p. 2; y Álvarez, Ayala, Iriondo, Martínez, Palacio y Ruiz-Huerta (1996), p. 51.
} 
que hay familias trabajadoras que invierten parte de sus ingresos y trabajadores retirados, en paro o rebajados, entre otros casos, que participan en las ganancias de las empresas. Además, dentro de este esquema, ¿en qué grupo deberían de clasificarse los autónomos? ${ }^{40}$ Por otro lado, un empresario puede actuar como tal aunque no disponga de ningún recurso productivo, incluido el capital necesario para el desarrollo de su negocio ${ }^{41}$.

En segundo lugar, existe cierta confusión sobre cómo deberían ser definidas las "rentas del trabajo" y las "rentas del capital". No cabe duda de que, dentro de los ingresos derivados del trabajo, el componente más importante es el salario, pero no es el único. Nos encontramos también con otras compensaciones, algunas de ellas en especie, sobre las que no hay acuerdo. Por ejemplo, no está claro si las aportaciones sociales, que suponen un beneficio diferido e indirecto para el trabajador, deberían incluirse dentro de este apartado. Tampoco existe un criterio unánime acerca de cómo han de ser considerados los subsidios estatales. Algo similar ocurre con los beneficios empresariales. Esta partida, principal componente de las rentas del capital, representa la retribución que corresponde al empresario por su labor dentro de la firma. Sin embargo, la remuneración del capital engloba otros muchos aspectos, pues, ¿qué ocurre con los impuestos, intereses, dividendos no repartidos o plusvalías?

La existencia de todas estas dificultades obliga a considerar con prudencia las estimaciones ofrecidas por los estudios realizados en este terreno, ya que pueden contener graves problemas por falta de homogeneidad. En particular, los estudios históricos cuentan con la dificultad añadida de las escasas fuentes estadísticas que, cuando existen, tampoco ofrecen una suficiente desagregación de las rentas como para poder afinar en las estimaciones. Ahora bien, también es cierto que al retroceder en el tiempo el solapamiento entre los ingresos del trabajo y del capital disminuye, pues nos encontramos con una estructura de clases mucho más rígida. Sólo hay que recordar que en las primeras décadas del siglo XX era más difícil que hoy en día que una familia trabajadora pudiera invertir en bolsa o en otro tipo de activos.

Lógicamente, los problemas comentados se trasladan y multiplican en los estudios que ofrecen comparaciones de las pautas distributivas en el ámbito internacional. Esto es debido a que, en primer lugar, pocos países disponen de series históricas continuas y homogéneas. En segundo lugar, en este tipo de análisis es necesario tener en cuenta las características del marco institucional vigente en cada país, ya que pueden generar discrepancias a la hora de definir y contabilizar las diferentes fuentes de ingreso.

\section{La distribución funcional del ingreso en España: las fuentes estadísticas ofi- ciales y el bagaje historiográfico}

\footnotetext{
40 Sobre las dificultades en la clasificación y cuantificación del autoempleo, Prados y Rosés (2003).

${ }^{41}$ Una reflexión muy interesante sobre este aspecto en Álvarez, Ayala, Iriondo, Martínez, Palacio y Ruiz-Huerta (1996), p. 52.
} 
La historiografía española acumula un notable atraso en la disponibilidad de estudios históricos sobre distribución funcional de la renta respecto a otros países, debido sobre todo a deficiencias estadísticas. De hecho, antes de la Guerra Civil, las fuentes estadísticas de carácter oficial no ofrecen datos sobre la distribución funcional de la renta en España. Posteriormente, en 1944, y dentro del Consejo de Economía Nacional, se creó la Comisión para la estimación de la cuantía y distribución de la Renta Nacional Española, con el propósito de estudiar tanto su volumen como su reparto. Sin embargo, los objetivos de esta Comisión no fueron plenamente atendidos, dando lugar a una laguna estadística importante. Efectivamente, los trabajos de la Contabilidad Nacional de España anteriores a los años sesenta pusieron un cierto orden en la información cuantitativa macroeconómica española, pero el déficit estadístico en este terreno es alarmante ${ }^{42}$.

En particular, las primeras estimaciones oficiales disponibles sobre distribución funcional de la renta en España parten de mediados de los años cincuenta. Estas cifras fueron publicadas con un considerable desfase temporal por el Instituto de Estudios Fiscales a finales de la década de 1960 (Cuadro 2). La metodología adoptada en esta estimación inicial de la Contabilidad Nacional define las rentas del trabajo y del capital en su acepción más amplia ${ }^{43}$. Así, por un lado, describe la Remuneración de Asalariados o Rentas del Trabajo como aquel conjunto de remuneraciones, en dinero o en especie, pagadas a los trabajadores como contraprestación a su aportación de trabajo al proceso productivo, incluyendo también las contribuciones a la Seguridad Social. A su vez, esta fuente descompone las rentas derivadas del trabajo en dos amplios grupos: aquéllas percibidas por cuenta ajena, mediante un contrato de trabajo, y las realizadas en trabajos por cuenta propia. Por otro lado, dentro del conjunto de rentas recibidas por la aportación de factor capital o Excedente Bruto de Explotación, la Contabilidad Nacional incluye las rentas de la propiedad y de la empresa (intereses, dividendos, y rentas de la tierra y de activos inmateriales), amortizaciones, impuestos directos, rentas mixtas y beneficios no distribuidos.

La demora en la publicación de estas primeras cifras oficiales impulsó al Servicio de Estudios del Banco de Bilbao a realizar una primera estimación sobre la distribución de la renta para 1955. La información estadística publicada por el Servicio de Estudios del Banco de Bilbao aporta una mayor desagregación de la distribución factorial de la renta nacional que la Contabilidad Nacional (Cuadro 3) ${ }^{44}$. Proporciona, además, una estimación de las rentas mixtas derivadas del trabajo y del capital aportado por trabajadores autónomos y profesionales liberales. Finalmente, el estudio del Banco de Bilbao considera un apartado especial para las rentas del sector público,

\footnotetext{
42 Alcaide (1974), p. 5.

${ }^{43}$ Siguiendo el argumento de Álvarez, Ayala, Iriondo, Martínez, Palacio y Ruiz-Huerta (1996), p. 60.

${ }^{44}$ Se puede observar una pequeña diferencia entre las estimaciones de los Cuadros 2 y 3 . Este sesgo puede tener su origen en los diferentes criterios metodológicos utilizados por ambas estimaciones: por un lado, la diferente agregación de las partidas; por otro, mientras la Contabilidad Nacional toma como unidad de referencia la Renta Nacional, el Banco de Bilbao considera la Renta Interior.
} 
mientras que la Contabilidad Nacional no contempla esta fuente de ingreso de forma aislada ${ }^{45}$. Aunque ninguna de estas dos estimaciones está exenta de serios problemas, sus datos han sido utilizados ampliamente por los historiadores españoles ${ }^{46}$.

\section{CUADRO 2}

COMPOSICIÓN INTERNA DE LA RENTA NACIONAL SEGÚN LA CONTABILIDAD NACIONAL DE ESPAÑA (porcentajes)

\begin{tabular}{|c|c|c|c|c|c|c|}
\hline & 1954 & 1955 & 1956 & 1957 & 1958 & 1959 \\
\hline Sueldos y Salarios & 50,13 & 50,38 & 50,51 & 50,27 & 49,94 & 51,61 \\
\hline De los sujetos a contrato (sin Seguridad Social) & 34,79 & 35,30 & 35,70 & 34,38 & 34,58 & 35,89 \\
\hline De los no sujetos a contrato de trabajo & 11,99 & 11,98 & 11,85 & 11,72 & 11,58 & 11,76 \\
\hline Contribución de los trabajadores a la SS & 0,84 & 0,77 & 0,75 & 1,01 & 0,92 & 0,97 \\
\hline Contribución de las empresas a la SS & 2,51 & 2,33 & 2,21 & 3,16 & 2,86 & 3,00 \\
\hline Rentas de los empresarios individuales & 28,46 & 28,25 & 28,54 & 29,29 & 28,91 & 28,44 \\
\hline Rentas agrícolas & 15,63 & 14,53 & 15,00 & 15,62 & 16,07 & 15,78 \\
\hline Rentas de las profesiones liberales & 2,42 & 2,33 & 2,12 & 2,09 & 2,07 & 2,15 \\
\hline Rentas de otras personas* & 10,40 & 11,39 & 11,42 & 11,58 & 10,77 & 10,52 \\
\hline Intereses, alquileres y dividendos ${ }^{\star *}$ & 12,46 & 12,41 & 12,14 & 11,28 & 11,01 & 9,55 \\
\hline Intereses & 3,29 & 3,17 & 3,37 & 3,12 & 3,04 & 3,21 \\
\hline Alquileres & 4,88 & 4,75 & 4,34 & 3,89 & 3,66 & 3,83 \\
\hline Dividendos & 4,28 & 4,49 & 4,44 & 4,28 & 4,30 & 2,52 \\
\hline Otros ${ }^{* * *}$ & 8,96 & 8,95 & 8,81 & 9,15 & 10,15 & 10,39 \\
\hline
\end{tabular}

* Que trabajan por cuenta propia o en asociación.

** Pagados a las economías domésticas e instituciones privadas sin fines de lucro.

*** Donativos, transferencias y rentas no distribuidas.

Fuentes: Instituto de Estudios Fiscales (1969), pp. 84-85.

\section{CUADRO 3}

COMPOSICIÓN INTERNA DE LA RENTA INTERIOR SEGÚN EL BANCO DE BILBAO

(porcentajes)

\begin{tabular}{|c|c|c|c|c|c|}
\hline & 1955 & 1956 & 1957 & 1958 & 1959 \\
\hline Rentas de trabajo (con Seguridad Social) & 46,48 & 46,08 & 45,55 & 45,71 & 47,25 \\
\hline En la industria & 16,80 & 16,58 & 16,52 & 17,15 & 17,64 \\
\hline En la agricultura & 4,00 & 4,22 & 4,34 & 4,44 & 5,04 \\
\hline En la pesca & 0,54 & 0,56 & 0,57 & 0,55 & 0,61 \\
\hline En los servicios & 18,54 & 18,41 & 17,81 & 17,50 & 17,90 \\
\hline Otras rentas al factor trabajo & 6,60 & 6,31 & 6,30 & 6,06 & 6,07 \\
\hline Rentas mixtas (capital y trabajo) & 33,42 & 34,02 & 34,90 & 33,68 & 32,85 \\
\hline Rentas agrarias & 15,38 & 16,02 & 16,84 & 17,50 & 17,21 \\
\hline Profesiones liberales y servicios personales & 5,56 & 5,38 & 5,36 & 5,34 & 5,56 \\
\hline Otros trabajadores autónomos y empresas & 12,48 & 12,62 & 12,69 & 10,84 & 10,08 \\
\hline Rentas de capital & 17,37 & 17,58 & 17,05 & 17,49 & 16,53 \\
\hline Beneficio retenido por sociedades y empresas & 5,74 & 6,18 & 6,39 & 7,02 & 5,61 \\
\hline Interés y dividendos* & 6,43 & 6,62 & 6,33 & 6,35 & 6,62 \\
\hline Renta de alquileres (incluso viviendas propias) & 5,19 & 4,79 & 4,32 & 4,12 & 4,31 \\
\hline Rentas del sector público** & 2,75 & 2,32 & 2,51 & 3,12 & 3,37 \\
\hline
\end{tabular}

* Pagados a familias e instituciones no lucrativas.

\footnotetext{
${ }^{45}$ Banco de Bilbao (1978), p. 38; Álvarez, Ayala, Iriondo, Martínez, Palacio y Ruiz-Huerta (1996), p. 79. ${ }^{46}$ Por ejemplo, en Maluquer (1989), p. 524; Espina (1990), p. 70; Molinero e Ysàs (1998), p. 88; o Barciela, López, Melgarejo y Miranda (2001), p. 331.
} 
** Impuestos directos a cargo de empresas y sociedades, así como también rentas patrimoniales del Estado.

Fuentes: Banco de Bilbao (1978), p. 50.

En general, la evidencia cuantitativa disponible sobre la distribución funcional del ingreso en España durante la segunda mitad de los años cincuenta, nos permite destacar esencialmente dos ideas. En primer lugar, el porcentaje correspondiente a las tres fuentes básicas de renta (trabajo, capital y propiedad) se mantuvo bastante estable durante este período. De hecho, en el caso de los ingresos derivados del trabajo y del capital es posible observar un comportamiento vacilante en el que se intercalan años de crecimiento y de caída. En segundo lugar, la participación de los ingresos salariales en la renta nacional española entre 1955 y 1959 es algo inferior a la observada en otros países de Europa occidental y en Estados Unidos durante esos años (Cuadro 1). Ahora bien, esta comparación ha de ser considerada con todas las precauciones por la heterogeneidad de los datos.

Para períodos anteriores a la cobertura temporal de estas fuentes, la mayor parte de la historiografía española ha tomado como referencia las hipótesis sobre distribución del ingreso apuntadas por J. Maluquer ${ }^{47}$. Simplificando el esquema distributivo propuesto por este autor, podemos señalar que durante la I Guerra Mundial y la inmediata posguerra "la parte del salario en la renta nacional tuvo que reducirse de forma notable". Durante la Dictadura de Primo de Rivera "pudo ser predominante el signo de la estabilidad, sin grandes modificaciones en la distribución". Los años de la crisis económica internacional y de la II República "habrían presenciado importantes cambios en la distribución, con un apreciable crecimiento de la participación de los salarios" ${ }^{48}$. Después de la Guerra Civil los pocos datos disponibles "transmiten una imagen de cierta estabilidad en la participación de las rentas salariales en la renta nacional neta al coste de factores entre 1939-1959". Pero, apunta el propio Maluquer, tampoco se puede considerar como "un disparate plantear la posibilidad de que el salario perdió peso dentro de la renta nacional".

En general, a pesar de la escasa evidencia cuantitativa, muchos historiadores económicos y sociales comparten la idea de que el desenlace de la Guerra Civil modificó la estructura de rentas vigente en las décadas anteriores ${ }^{49}$. En particular, la mayor parte de la literatura sostiene que el principal objetivo de los que iniciaron y ganaron esta guerra era invertir las tendencias crecientes, favorables al trabajo y contrarias al capital $^{50}$. Así, una vez terminado el conflicto, el régimen franquista desarrolló una

${ }^{47}$ Maluquer (1989, p. 510) señala que tales hipótesis son provisionales a falta de mayor evidencia cuantitativa.

${ }^{48}$ Las estimaciones de Palafox (1991) indican que la participación de las rentas salariales en el ingreso nacional, entre 1926 y 1935, aumentó alrededor de un 26 por 100. Por su parte, Comín (1994, p. 128) señala que tanto la Dictadura como la República pudieron haber mejorado la situación de los trabajadores. La primera pudo favorecer el empleo, pero frenando el crecimiento de los salarios reales, y la segunda pudo haber mejorado los salarios reales y las condiciones de trabajo, pero a costa de un incremento del paro.

${ }^{49}$ Desde un punto de vista más social, un vasto conjunto de obras aporta pruebas de fuertes cambios sociales en la inmediata posguerra civil, por ejemplo, Cazorla (2000) o Mir (2002).

${ }^{50}$ Carreras (1989), p. 12. Véanse también Fontana y Nadal (1980), pp. 141-145; Maluquer (1989), p. 510; Catalan (1995), p. 273; Molinero e Ysàs (1998), pp. 45 y 262; o Prados (2003), p. 160, entre otros. 
política sistemática de anulación de los avances sociales y políticos alcanzados durante la II República con el único fin de restaurar "el viejo orden social" 51 . Dentro de este nuevo marco institucional de posguerra, el Estado aparece como un gigantesco mecanismo de redistribución de la renta en un sentido socialmente regresivo, sobre todo durante el período autárquico ${ }^{52}$.

Partiendo de este tronco común, nos encontramos con diferentes líneas de investigación. Uno de estos enfoques analiza las redes de intereses que se establecieron entre algunos empresarios y los políticos franquistas buscando el beneficio mutuo. Así, los primeros, aprovechándose de sus estrechas relaciones con las autoridades del régimen, lograron acumular importantes beneficios a través de mecanismos de acumulación que a menudo sobrepasaban el filo de la ley ${ }^{53}$. Otros autores analizan estos aspectos desde la perspectiva de los trabajadores, poniendo un énfasis especial en el marco laboral represivo y la falta de libertades vigente tras la Guerra Civil ${ }^{54}$. Dentro del nuevo marco institucional de posguerra la capacidad de negociación de los trabajadores era prácticamente nula, al no disponer de unos sindicatos eficaces ni de derecho de huelga. Tampoco poseían la capacidad de actuar como grupos de presión, tal y como ocurría con otros sectores sociales, por lo que permanecieron al margen de las redes de influencias. Por tanto, los trabajadores quedaron a merced de un marco laboral claramente desfavorable que les despojaba de todas las vías posibles para defender su participación en la renta nacional ${ }^{55}$.

En realidad, podemos afirmar que, cualquiera que sea la perspectiva de análisis, la mayor parte de los estudios realizados por la historiografía española en el ámbito de la distribución comparten un objetivo común: la búsqueda de nuevas evidencias de que la penuria económica de la posguerra civil no afectó a todos por igual. La idea de que en este período las distancias sociales entre los propietarios de los medios de producción y los trabajadores aumentaron está presente en la mayor parte de las conclusiones. El siguiente apartado pretende caminar en esta dirección, ofreciendo nueva evidencia cuantitativa que permita contrastar empíricamente estos argumentos.

\section{Los beneficios empresariales y la masa salarial en la industria española: una vía de aproximación a las pautas distributivas}

A partir de los beneficios empresariales y los salarios industriales podremos aproximarnos parcialmente, desde un punto de vista macro, al comportamiento de los ingresos derivados del factor capital y del trabajo en España entre 1914 y 1959. Lógicamente, estas estimaciones no son equivalentes a las rentas del trabajo y del capital

\footnotetext{
${ }^{51}$ Barciela (2002), p. 331.

52 Tafunell (2000), pp. 81-82.

${ }^{53}$ Barciela (1998), Catalan (2003), y Sánchez y Tascón (2003).

${ }^{54}$ Catalan (1995) y Vilar (2006).

${ }_{55}$ Vilar (2006) y la bibliografía citada.
} 
ofrecidas por la Contabilidad Nacional, pues, como ya se ha comentado, su grado de representatividad es limitado ${ }^{56}$. Sin embargo, estas dos series son un buen punto de partida para elaborar un primer indicador suficientemente válido que nos permita capturar los principales cambios en las tendencias distributivas de la economía española en el período objeto de estudio.

El cálculo de la masa salarial en la industria española exige estimar previamente el número de asalariados pertenecientes a este sector entre 1914 y 1959. El principal obstáculo radica en que no disponemos de datos anuales sobre la población ocupada en España hasta 1964, cuando el Instituto Nacional de Estadística comenzó a elaborar periódicamente la Encuesta de Población Activa. Abordar la cuantificación del número de trabajadores y su distribución por sectores productivos antes de esa fecha presenta serios problemas, debido a la naturaleza de las fuentes con las que se enfrenta la historiografía española ${ }^{57}$. De hecho, ante la falta de otras alternativas, la mayoría de los trabajos realizados en este ámbito para el conjunto de la economía española ha utilizado como fuente de referencia los censos de población ${ }^{58}$. Pero no podemos olvidar que los datos censales antes de 1960 muestran graves limitaciones metodológicas y cuantitativas que exigen un análisis crítico previo a su utilización. En términos generales, podemos destacar dos problemas principales.

En primer lugar, el registro de activos industriales en los censos es deficiente desde al menos tres puntos de vista. Por un lado, como ya se ha mencionado, esta fuente presenta un grave problema de infravaloración del trabajo femenino ${ }^{59}$. Los datos censales, además, no contabilizan el trabajo sumergido de los activos industriales que desarrollaban su actividad a destajo en su domicilio o en pequeños talleres de carácter familiar. Finalmente, los censos presentan serios problemas de cuantificación cuando una misma persona desempeña diferentes actividades laborales durante el año, una situación habitual en las economías en desarrollo. En estos casos, los censos computan por lo general una única actividad, la que los individuos consideraban principal, y ésta suele estar relacionada con las tareas agrícolas. Como consecuencia, el recuento de los trabajadores no agrícolas resulta claramente infravalorado ${ }^{60}$.

En segundo lugar, no existe homogeneidad de criterios de un corte censal a otro, ni en cuanto a la recopilación de la información, ni respecto del tratamiento de los datos, lo que dificulta las comparaciones a lo largo del tiempo ${ }^{61}$. De hecho, los

\footnotetext{
${ }^{56}$ Recordemos que la Contabilidad Nacional presenta estos dos agregados macroeconómicos (rentas del trabajo y del capital) en su acepción más amplia. Pero dentro de nuestra estimación sólo se considera la masa salarial (monetaria y sin cotizaciones sociales ni autoempleo) que perciben los trabajadores asalariados en la industria española y los beneficios empresariales que representan a una parte de las rentas del capital.

${ }^{57}$ Más comentarios en Arbaiza (2000), p. 457.

${ }^{58}$ En ocasiones los datos censales se han completado con las informaciones eventuales recopiladas por otras fuentes de ámbito más restringido; véase Soto (1989), p. 29.

${ }^{59}$ Véase la nota 20.

${ }^{60}$ Prados (2003), p. 167.

${ }^{61}$ Nicolau (1989), p. 83; Soto (1989), p. 19; Pérez-Fuentes (1995), p. 222; Arbaiza (2000), p. 457; y Sarasúa y Gálvez (2003), p. 11.
} 
censos presentan saltos cuantitativos incoherentes respecto a los activos pertenecientes a algunos sectores, lo que induce a dudar de la veracidad de la información ${ }^{62}$. Como consecuencia, los datos censales resultan claramente deficientes, pero hasta el momento no disponemos de una alternativa mejor con similar grado de cobertura.

Condicionados por esta realidad, en este trabajo se utiliza como base para el cálculo de la masa salarial en la industria la serie de empleo industrial (incluida la construcción) ofrecida por Prados (2003). Esta estimación está elaborada por medio de interpolaciones a partir de los datos de población activa que proporcionan los censos de población ${ }^{63}$. Su principal ventaja es que proporciona una serie anual continua entre 1914 y 1959 que cumple unas ciertas garantías de homogeneidad y ofrece un aceptable grado de representatividad ${ }^{64}$. En definitiva, aunque arrastra todos los problemas de la información facilitada por los censos, constituye la opción menos mala para poder aproximarnos a la evolución anual del trabajo en la industria española desde una perspectiva de largo plazo ${ }^{65}$. Ahora bien, como sólo disponemos de datos de salarios industriales masculinos, hay que eliminar de esta serie a las trabajadoras industriales. Para realizar este ajuste, se ha reconstruido desde las cifras finales hacia atrás el proceso seguido por Prados para la elaboración de su serie de empleo ${ }^{66}$.

Como resultado de esta estimación obtenemos una serie de empleo industrial que crece continuamente entre 1914 y 1935, aunque con una mayor intensidad desde los años veinte (véase el Apéndice 1). Efectivamente, antes de la Guerra Civil y dentro de un contexto de modernización industrial, cambio estructural y desarrollo urbano, tuvo lugar un notable trasvase de población del campo a la ciudad que implicó un aumento del empleo industrial ${ }^{67}$. Por el contrario, después del conflicto se pueden observar dos tendencias muy diferentes. En primer lugar, el empleo industrial sufrió una fuerte contracción en los años cuarenta dentro de un contexto de crisis económica, carestía y escasez de los alimentos. Ante la falta de oportunidades de trabajo en el ámbito urbano y las dificultades derivadas del racionamiento y el mercado negro, muchas familias decidieron regresar al campo, donde aún mantenían lazos familiares y podían cubrir más fácilmente sus necesidades alimenticias. En segundo lugar, tras

\footnotetext{
${ }^{62}$ Las deficiencias que presentan los censos obligan a adoptar supuestos de partida para tratar la información primaria de la forma más homogénea posible. Como consecuencia de los diferentes criterios de trabajo utilizados para computar y clasificar a los individuos por categorías profesionales nos encontramos con distintas estimaciones de activos industriales. Véanse Nicolau (1989), p. 78; Soto (1989), p. 57; y FOESSA (1975), p. 717.

${ }_{63}$ Tal y como indica Prados (2003, pp. 206-208, especialmente nota 314), su estimación parte de los porcentajes de activos ofrecidos por Nicolau (1989), cuadro 2.16.

64 Prados (2003), p. 206.

${ }^{65}$ Los censos no proporcionan datos sobre el desempleo involuntario a largo plazo, pero Prados (2003, p. 206) resta importancia a este sesgo "dentro de una economía de base agraria como la española antes de 1960 donde el desempleo en sentido moderno del término era muy reducido, salvo crisis excepcionales como la de los años treinta".

${ }^{66}$ Es decir, como la serie de Prados (2003) parte de la información facilitada por Nicolau (1989), se han deducido las trabajadoras industriales utilizando los porcentajes de población activa industrial femenina ofrecidos por esta autora.

${ }^{67}$ Véase, por ejemplo, Silvestre (2003), p. 76, y la bibliografía citada.
} 
este bache de la posguerra el éxodo rural adquirió de nuevo importancia a finales de los años cuarenta, a medida que la economía española lograba recuperar de nueve la senda del crecimiento. Como consecuencia, el empleo industrial experimentó un intenso incremento en la década de los cincuenta.

Como siguiente paso para el cálculo de la masa salarial se han establecido, por término medio, 300 jornadas ordinarias de trabajo al año por cada asalariado industrial ${ }^{68}$. Sin embargo, no podemos olvidar que el desempeño de horas extraordinarias o el pluriempleo han sido históricamente recursos habituales de las familias trabajadoras para hacer frente a las coyunturas de crisis económica como la de la posguerra $^{69}$. Como consecuencia, resultaba habitual que un obrero trabajase en más de una ocupación o realizando horas extras en un único puesto de trabajo hasta completar una jornada de 10, 12 ó 14 horas $^{70}$. Estas conductas quedaron gravadas en la memoria popular, pero apenas fueron recogidas por las publicaciones oficiales de la época, que sólo ofrecen información sobre la jornada ordinaria de trabajo. Este vacío estadístico, muy probablemente deliberado, podría responder a la intención por parte del régimen de silenciar lo que estaba sucediendo en el mercado de trabajo.

Con el fin de poder evaluar el impacto de esta situación se ofrecen dos estimaciones alternativas. En primer lugar, se ha mantenido constante el número de jornadas de trabajo para todo el período objeto de estudio (300). Este supuesto es bastante irreal para el lapso de posguerra, dadas las condiciones económicas y laborales imperantes. Sin embargo, nos permite analizar la evolución de la masa salarial sin tener en cuenta el impacto de posibles cambios en la jornada laboral. En segundo lugar, se ha considerado que, por término medio, un trabajador industrial, tras la Guerra Civil, se vio obligado a trabajar al menos dos horas extra cada día para completar sus ingre$\operatorname{sos}^{71}$. Bajo este supuesto, este trabajador habría cubierto al cabo del año un número de horas equivalente a 375 jornadas ordinarias de trabajo (300-375).

Finalmente, se ha construido la ratio entre la masa salarial en la industria y los beneficios empresariales entre 1914 y 1959 (Gráfico 1). Su comportamiento a largo plazo muestra unas tendencias muy dispares antes y después de la Guerra Civil. Así, mientras que en las décadas anteriores al conflicto los trabajadores asalariados fueron absorbiendo una proporción cada vez mayor de renta - aunque con alguna excepción-, en la posguerra esta tendencia se invirtió por completo. Desde esta perspectiva, no cabe duda de que la dictadura franquista modificó profundamente la estructura de rentas vigente en el período prebélico. Partiendo de estas pautas generales de

\footnotetext{
${ }^{68}$ Una cifra habitual en este tipo de estimaciones, calculada a partir del producto de 52 semanas por año y 6 días de trabajo por semana, un total de 312 jornadas laborales, de las que suelen descontarse 12, correspondientes a las vacaciones, las fiestas locales o las posibles bajas laborales por enfermedad. Véase, por ejemplo, Palafox (1991), p. 314. A este respecto, Soto (1989, p. 623) señala que durante las décadas anteriores a la Guerra Civil el trabajo obrero "venía siendo una labor continuada que sólo encontraba paréntesis en los domingos y en las fiestas; fuera de dichos días [...], el trabajo era la norma". ${ }^{69}$ Un análisis detallado sobre esta cuestión en Vilar (2006), p. 147.

${ }^{70}$ Molinero e Ysàs (1985), p. 109, y Babiano (1995), p. 125.

${ }^{71}$ Vilar (2006), p. 148.
} 
comportamiento, la información facilitada por esta ratio demanda un análisis más exhaustivo.

\section{GRÁFICO 1}

RELACIÓN ENTRE LA MASA SALARIAL Y LOS BENEFICIOS EMPRESARIALES, 1914-1959

(según dos estimaciones del número anual de jornadas de trabajo)

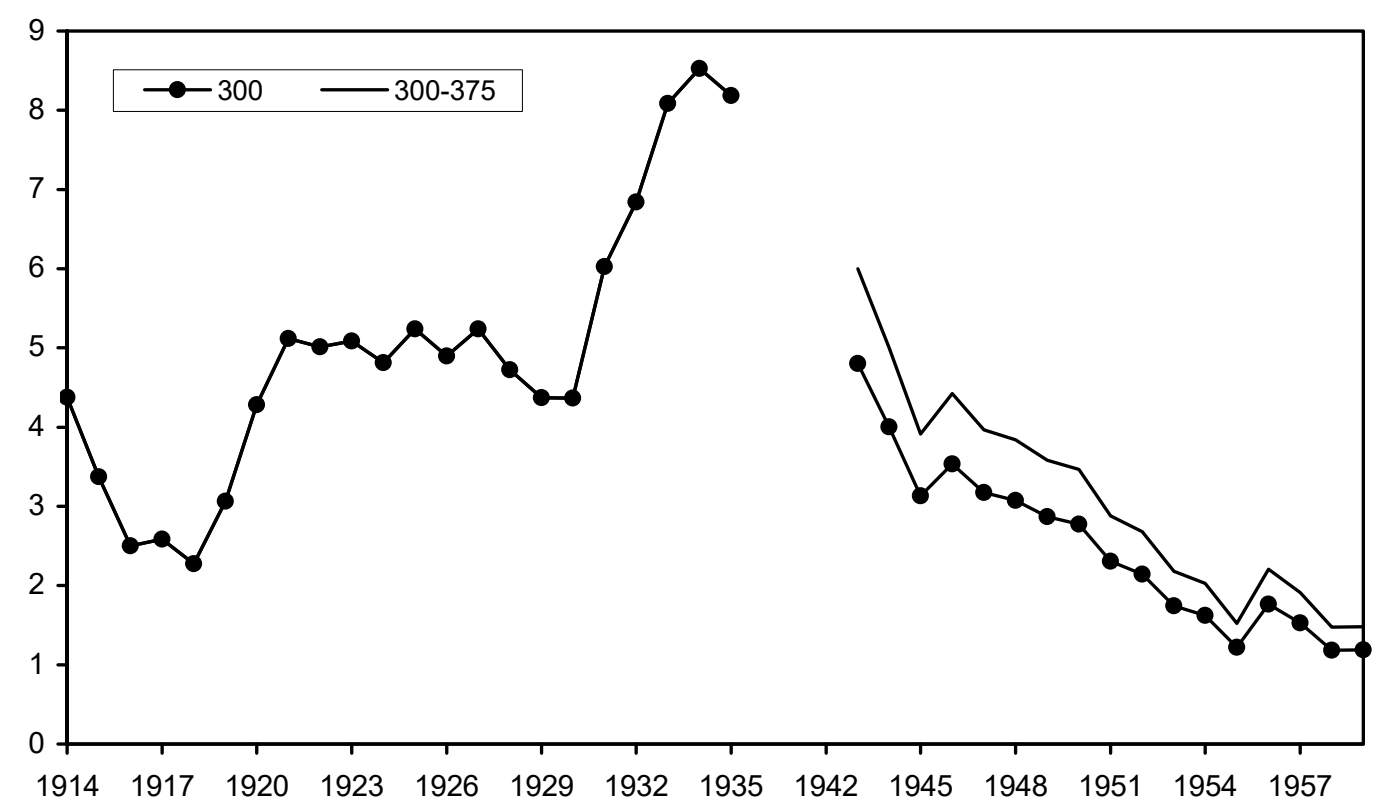

Fuentes: Apéndice 1.

En primer lugar, centrando la atención en el período prebélico, es posible observar el impacto causado por la I Guerra Mundial en la economía española desde el punto de vista distributivo. En particular, la evidencia empírica revela que, entre 1914 y 1918, los beneficios empresariales crecieron más que la masa salarial, a pesar de que tanto los salarios nominales como el empleo industrial aumentaron durante esos años ${ }^{72}$. En esta coyuntura bélica, la posición neutral de España permitió que muchas industrias nacionales obtuvieran importantes beneficios en un contexto inflacionista dominado por el funcionamiento irregular de los mercados exteriores ${ }^{73}$. Para cubrir el aumento extraordinario de la demanda, muchas industrias recurrieron a la ampliación de la jornada de trabajo, efecto que no captura la serie analizada. Sin embargo, es muy poco probable que los ingresos salariales recibidos por estas horas extraordinarias pudieran compensar la caída de la ratio en la coyuntura bélica ${ }^{74}$.

La relación entre los ingresos del trabajo industrial y los beneficios ofrece una trayectoria muy diferente entre 1918 y 1921. En este período, mientras el salario industrial aumentaba por término medio, los beneficios empresariales caían ${ }^{75}$. Dos fac-

\footnotetext{
72 Un resultado acorde con la tesis de Roldán y García Delgado (1973) o Tafunell (1996). Es necesario aclarar que, entre 1914 y 1918, los salarios industriales nominales aumentaron pero la inflación creció todavía más (Vilar, 2004b).

${ }^{73}$ Roldán y García Delgado (1973), Maluquer (1994), Sudrià (1990) y Comín (2002). Debe puntualizarse que no todos los sectores industriales se vieron beneficiados por el conflicto (Tafunell, 2000, pp. 79-81). ${ }^{74}$ En la línea del argumento ofrecido por Carreras y Tafunell (2003), p. 231.

75 Tafunell (1998), p. 727, y Vilar (2004b), p. 94.
} 
tores pueden estar detrás de este comportamiento. Por un lado, tras el fin de la coyuntura bélica extraordinaria, los mercados internacionales se regularizaron y la economía española volvió a sufrir la competencia exterior ${ }^{76}$. Por otro, los costes de las empresas españolas aumentaron. En particular, los salarios crecían impulsados por las presiones de las organizaciones obreras, a la vez que se extendía la jornada laboral de ocho horas en la industria (1919) ${ }^{77}$. Como consecuencia, la serie analizada corrobora la hipótesis que defiende que el ciclo bélico fue un recorrido completo de ida y vuelta; de forma que la relación entre los ingresos salariales y los beneficios hacia 1921 era muy similar a la existente en $1914^{78}$.

Según la evidencia ofrecida en el Gráfico 1, los años veinte y treinta presentan dos claras tendencias en la evolución de las series analizadas. Mientras la Dictadura de Primo de Rivera favoreció en mayor medida los intereses de los empresarios, la II República jugó más a favor de los asalariados industriales ${ }^{79}$. Ahora bien, además de ofrecer esta pauta general, la evolución de la ratio analizada permite introducir un importante matiz. Parece que las rentas salariales en la industria se vieron relativamente más favorecidas bajo el régimen republicano que los beneficios empresariales bajo el régimen dictatorial.

En particular, de acuerdo con la estimación de Tafunell (1998), los beneficios nominales aumentaron entre 1921-1930 y 1933-1935 (con la excepción de los años 1925 y 1927) y disminuyeron suavemente entre 1930-1933. Según este comportamiento, hay que descartar la idea de que los excedentes empresariales se hundieran en los años treinta, a pesar de la crisis económica y el clima de desconfianza empresarial hacia los gobiernos republicanos ${ }^{80}$. Por su parte, la estimación de Vilar (2004b) muestra que los salarios nominales masculinos en la industria aumentaron por término medio durante todo el período, así como también el número de asalariados en este sector, si bien es cierto que la tasa de crecimiento de los salarios fue mayor entre 1931 y 1935 que en la década precedente. Por tanto, en este caso los datos revelan que los salarios industriales aumentaron en el período de desarrollo industrial de la Dictadura, a pesar de la política corporativista y de la prohibición de la huelga ${ }^{81}$.

Para entender este resultado es necesario recordar también que en las décadas anteriores a la Guerra Civil la legislación del trabajo en España se amplió de forma notable ${ }^{82}$. En un contexto de modernización económica y aceleración de cambios estructurales, fueron tomando forma las nuevas normas de contratación y negociación salarial, a la vez que se extendía un incipiente sistema de seguros sociales. De forma paralela, entre 1913 y 1935, el gasto público creció discretamente y experimentó un

\footnotetext{
${ }^{76}$ Comín (2002), p. 289.

77 Soto (1989), p. 424.

${ }^{78}$ Carreras y Tafunell (2003), p. 231, y Comín (2002), p. 187.

${ }^{79}$ Corroborando la tesis tradicional, véase Comín (1994), p. 128.

80 Prados (2003), p. 159, y Carreras y Tafunell (2003), p. 252.

${ }^{81}$ Una conclusión compartida por Comín (1988), p. 828.

${ }^{82} \operatorname{Vilar}(2004 a)$, cap. 2.
} 
módico cambio estructural ${ }^{83}$. No obstante, en este terreno hubo notables diferencias entre la Dictadura de Primo de Rivera y la II República. Fue precisamente en este segundo período cuando la actuación del Estado, a través de la legislación social y la intervención sindical en la negociación colectiva, fue más intensa. Ambos instrumentos, con importantes efectos redistribuidores, tuvieron que actuar a favor del factor trabajo a principios de los años treinta.

A diferencia de lo ocurrido en las décadas anteriores, la evidencia empírica muestra que la masa salarial en la industria durante la posguerra no solo perdió terreno frente a los beneficios empresariales, sino que también evolucionó, en términos relativos, peor que la producción industrial (Gráficos 1 y 2) ) $^{84}$. Este resultado alcanza mayor importancia si tenemos en cuenta que el nivel de producción industrial en la posguerra tardó once años en recuperar el valor alcanzado en $1935^{85}$. Atendiendo a este comportamiento, no cabe duda de que los trabajadores asalariados fueron los que soportaron principalmente el deterioro de la realidad económica durante la inmediata posguerra. Estas consecuencias negativas se vieron agravadas por la espiral inflacionista vigente en ese período.

\section{GRÁFICO 2}

RELACIÓN ENTRE LA MASA SALARIAL Y LA PRODUCCIÓN INDUSTRIAL, 1914-1959

(según dos estimaciones del número anual de jornadas de trabajo)

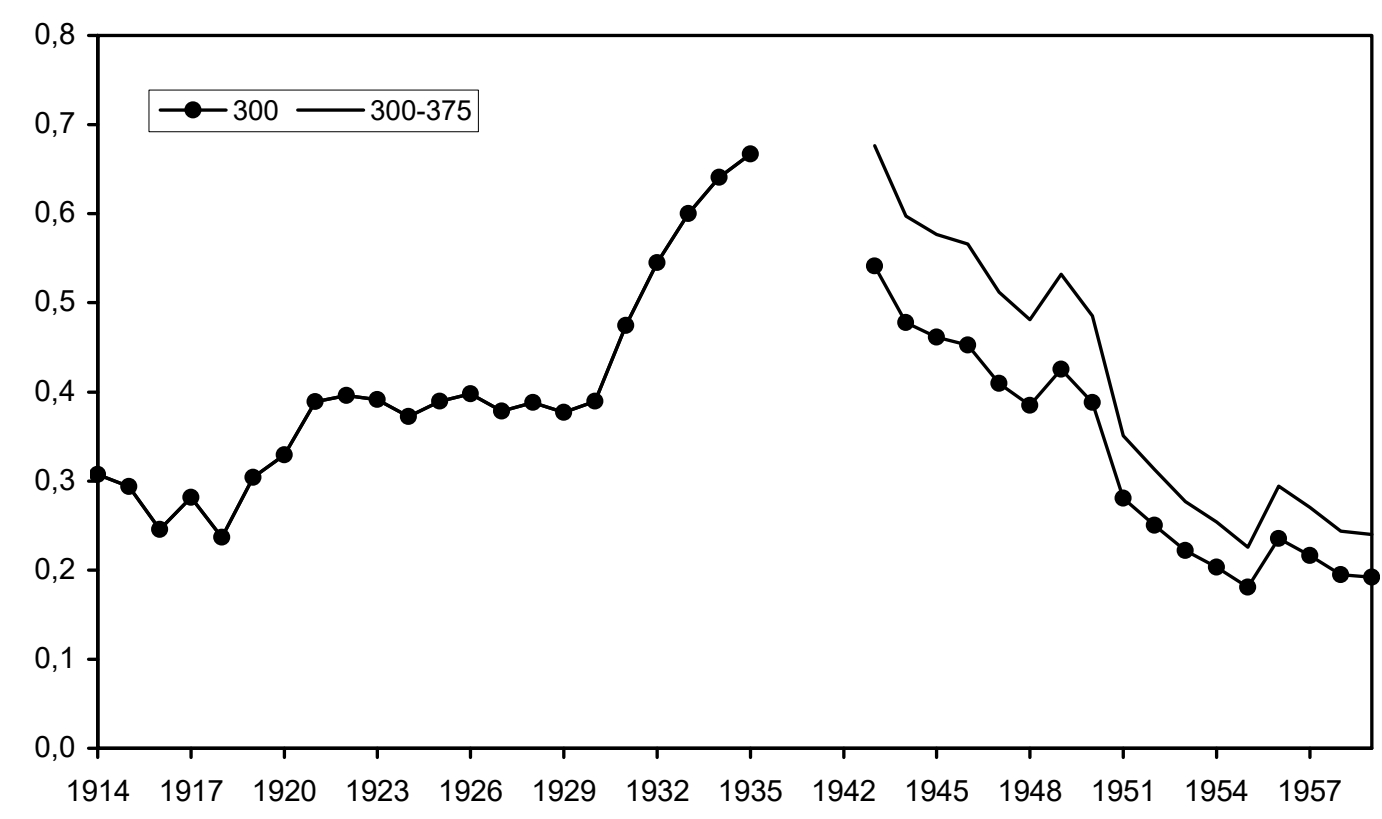

Fuentes: Apéndice 1.

\footnotetext{
83 Comín (2002), p. 316.

${ }^{84}$ Sólo las mejoras salariales a golpe de decreto lograron frenar en años puntuales la caída continuada de la masa salarial frente a los beneficios y la producción (Vilar, 2004b, p. 124). En el Gráfico 2 se ha utilizado la producción industrial en vez del PIB total porque la economía española presentaba una estructura básicamente agraria entre 1914 y 1959. En consecuencia, el PIB estaba muy condicionado por las fluctuaciones del sector primario, lo que podría introducir distorsiones en el análisis.

${ }^{85}$ Prados (2003).
} 
La alarmante pérdida continuada de poder adquisitivo obligó a muchas familias a adoptar estrategias colectivas de supervivencia ${ }^{86}$. Además, el restrictivo marco salarial de posguerra forzó a numerosas empresas a poner en práctica dos tipos de actuaciones para completar los ingresos de sus trabajadores. De un lado, ofrecieron servicios de comedor, economato y otros pagos en especie, para que los trabajadores pudieran acceder al consumo de una amplia gama de productos a precios inferiores a los de mercado. De otro, recurrieron a pagos salariales clandestinos, aunque obviamente es imposible valorar en qué cuantía.

La consideración de los trabajadores sumergidos y de las mujeres, así como también de estas retribuciones complementarias, habría elevado lógicamente el cómputo ofrecido de la masa salarial en la industria tras la Guerra Civil. Las restricciones estadísticas no nos permiten cuantificar este ajuste al alza. Pero, si tenemos en cuenta que esos dos grupos de activos excluidos recibían por lo general unos salarios más bajos que los trabajadores computados por la estadística oficial, parece muy poco probable que su consideración hubiera podido invertir la aguda trayectoria descendente de la ratio en este período ${ }^{87}$.

En los años cincuenta los resultados de la economía española fueron mucho mejores que los alcanzados en la década precedente, gracias sobre todo a la introducción de importantes reformas institucionales. Tradicionalmente, esta década es considerada como una etapa de transición entre el período más autárquico e intervencionista del franquismo y el Plan de Estabilización, que permitió la aplicación de nuevas políticas pro-mercado, a la vez que se introducían profundas transformaciones económicas ${ }^{88}$. Dentro de este nuevo contexto, la economía española recuperó la senda del crecimiento, así como también los cambios estructurales que acompañan habitualmente a los procesos de modernización.

A diferencia de otros aspectos, la relación entre los ingresos del trabajo y el capital mantuvo su trayectoria descendente. Esta caída persistente puede responder a la ausencia de profundas reformas estructurales en el mercado de trabajo. De hecho, los aires reformistas de esta década apenas modificaron las características básicas del marco laboral establecido por el régimen franquista en la inmediata posguerra. En general, los derechos básicos de los trabajadores seguían sin ser reconocidos, mientras que los aumentos salariales siguieron encontrando fuertes obstáculos.

Bajo estas circunstancias, los insuficientes aumentos salariales, junto con el aumento del empleo industrial, no bastaron para compensar el fuerte crecimiento de la producción y los beneficios (Gráficos 1 y 2) ${ }^{89}$. Así, por un lado, la tasa media anual de crecimiento de la producción industrial española entre 1952 y 1958 ascendió a 7,45

\footnotetext{
${ }^{86}$ Siguiendo el argumento de Vilar (2006), p. 137. Ahora bien, no se puede identificar una caída de los ingresos salariales en la renta nacional con un deterioro en el nivel de vida de los asalariados, pues habría que considerar la evolución conjunta de la producción, los salarios, el número de asalariados y la inflación.

${ }^{87}$ Pueden encontrarse datos salariales parciales sobre estos activos excluidos en Vilar (2006), p. 151.

${ }^{88}$ Barciela (2002), p. 359.

${ }^{89}$ Véase Vilar (2004b), pp. 99-100.
} 
por 100, una de las más altas alcanzadas en los últimos ciento cincuenta años ${ }^{90}$. Por otro lado, la tasa de crecimiento de los beneficios entre 1950 y 1960 fue una de las más elevadas desde un punto de vista histórico (10,36 por 100). No cabe duda de que las nuevas oportunidades que ofrecía el cambio de rumbo de la política económica y la recuperación del proceso de modernización imprimieron un formidable impulso a los beneficios ${ }^{91}$. Sin embargo, los asalariados no conseguían recuperar el poder adquisitivo que habían disfrutado antes del estallido de la Guerra Civil ${ }^{92}$. Por lo tanto, según los datos disponibles, el marco institucional de posguerra siguió favoreciendo claramente a los empresarios frente a los trabajadores, al menos hasta 1959. Durante estos primeros veinte años de dictadura los trabajadores, privados por métodos coercitivos de cualquier vía de reivindicación, poco pudieron hacer por defender su participación en la renta generada.

\section{Conclusiones}

Las graves deficiencias de las estadísticas históricas sobre la distribución de la renta en España nos obligan a buscar vías de análisis alternativas para obtener nueva evidencia cuantitativa suficientemente sólida para apoyar nuestros argumentos. Este trabajo ha ofrecido una nueva herramienta cuantitativa, la ratio entre los ingresos salariales de los trabajadores industriales y los beneficios empresariales, que permite aproximarnos a la evolución a largo plazo de las rentas del trabajo y el capital en la industria española. Obviamente, este indicador, que viene a complementar a otros ya existentes en la historiografía española, se ha de ir mejorando en el futuro.

Su comportamiento a largo plazo nos ha permitido, en primer lugar, establecer algunos matices interesantes sobre la evolución de las pautas distributivas antes y después de la Guerra Civil. En segundo lugar, nos ha brindado la posibilidad de comprobar desde un punto de vista empírico que el desenlace de la Guerra Civil no afectó a todas las fuentes de renta por igual. En particular, la evidencia empírica indica que la acumulación de ingresos a través de los beneficios empresariales en la posguerra se consiguió en gran parte a costa de los asalariados. Atendiendo a este comportamiento, no cabe duda de que los grupos sociales menos pudientes, encabezados por los trabajadores, soportaron, en su mayor parte, el deterioro de la realidad económica en los años cuarenta. El armazón económico, político y social establecido por la dictadura contribuyó a descargar los costes económicos sobre los trabajadores que constituían el eslabón más débil de la cadena de producción y de la estructura de clases. Por otro lado, ese mismo armazón favoreció que los empresarios fueran los principales beneficiados de la recuperación económica de los años cincuenta. Como consecuencia, la desigualdad en el reparto de la renta entre los factores trabajo y capital siguió aumentando en esta década.

\footnotetext{
${ }^{90}$ Según las tasas medias anuales en porcentaje de Prados (2003), p. 201.

91 Tafunell (1998), p. 732.

92 Vilar (2006), p. 140.
} 
Asistimos, por tanto, a un modelo de funcionamiento de la economía española en la posguerra muy alejado del patrón distributivo seguido por las economías capitalistas más avanzadas tras la II Guerra Mundial. En éstas, se asumió el compromiso de construir un nuevo orden social que garantizase un futuro de paz y prosperidad económica sobre unas bases democráticas ${ }^{93}$. Con este fin, se impulsó la colaboración entre sindicatos, patronal y Estado para alcanzar los fines de bienestar y acumulación de capital propios del keynesianismo ${ }^{94}$. Obviamente, la realidad política de la España de posguerra no encajaba dentro de este esquema, y la dictadura franquista no tuvo intención de introducir ningún correctivo para compensar las enormes desigualdades sociales que se estaban generando ${ }^{95}$.

\section{Bibliografía}

ALCAIDE, Julio (1974): “Así se distribuye la riqueza y la renta en la sociedad española", Revista Sindical de Estadística, 116, pp. 2-32.

ÁLVAREZ, Carlos; AYALA, Luis; IRIONDO, Ignacio; MARTÍNEZ, Rosa; PALACIO, Juan I., y RUIZ-HUERTA, Jesús (1996): La distribución funcional y personal de la renta en España. Un análisis de sus relaciones, Madrid, CES.

ARBAIZA, Mercedes (2000): “La 'cuestión social' como cuestión de género. Feminidad y trabajo en España (1860-1930)", Historia Contemporánea, 21, pp. 395-458.

ARENAS, Carlos (2003): Historia económica del trabajo (siglos XIX y XX), Madrid, Tecnos.

ATKINSON, Anthony B., y BOURGUIGNON, Francois (eds.) (2000): Handbook of Income Distribution, 1, Amsterdam, Elsevier Science.

AUBANELL, Anna M. (1994): “La gran empresa en España (1917-1974). Una nota crítica", Revista de Historia Industrial, 5, pp. 163-170.

BABIANO, José (1995): Emigrantes, cronómetros y huelgas. Un estudio sobre el trabajo y los trabajadores durante el franquismo (Madrid, 1951-1977), Madrid, Siglo XXI.

BANCO DE BILBAO (1978): Renta Nacional de España y su distribución provincial. Serie homogénea 1955-1975, Bilbao, Banco de Bilbao.

BARBER, William J. (1988): Historia del pensamiento económico, Madrid, Alianza.

BARCIELA, Carlos (1998): "Franquismo y corrupción económica”, Estudios de Historia Social, 30, pp. 83-96.

-(2002): “Guerra Civil y primer franquismo (1936-59)", en COMÍN, Francisco, HERNÁNDEZ, Mauro, y LLOPIS, Enrique (eds.), Historia económica de España, siglos X-XX, Barcelona, Crítica, pp. 331-368.

BARCIELA, Carlos; LÓPEZ, Ma Inmaculada, MELGAREJO, Joaquín, y MIRANDA, José A. (2001): La España de Franco (1939-1975), Madrid, Síntesis.

\footnotetext{
${ }^{93}$ Barciela (2002), p. 349.

${ }^{94}$ Arenas (2003), p. 205.

${ }_{95}$ De hecho, el sistema fiscal fue claramente regresivo y el gasto social se mantuvo mal distribuido y muy bajo con relación al PIB. Véase Comín (1996).
} 
BARRO, Robert (1999): Inequality, Growth and Investment, NBER, Working Paper, 7038.

BÉRTOLA, Luis (2005): “A 50 años de la curva de Kuznets: crecimiento económico y distribución del ingreso en Uruguay y otras economías de nuevo asentamiento desde 1870", Investigaciones de Historia Económica, 3, pp. 135-176.

BETRÁN, Concha (1994): “El fraude fiscal en la industria: España, 1913-1929. El impuesto de utilidades", Hacienda Pública Española, 2, pp. 309-319.

BRENNER, Yehojachin; KAELBLE, Harmut, y THOMAS, Mark (eds.) (1991): Income Distribution in Historical Perspective, Cambridge, Cambridge University Press.

CAMPS, Enriqueta (1997): "Las transformaciones del mercado de trabajo en Cataluña (1850-1925): migraciones, ciclos de vida y economías familiares", Revista de Historia Industrial, 11, pp. 45-71.

CARRASCO, Cristina, y MAYORDOMO, Maribel (2000): “Los modelos de estadísticas de empleo como construcción social: la encuesta de población activa y el sesgo de género", Política y Sociedad, 34, pp. 101-112.

CARRERAS, Albert (1989): “Depresión económica y cambio estructural durante el decenio bélico (1936-1945)", en GARCÍA DELGADO, José L. (ed.), El primer franquismo. España durante la Segunda Guerra Mundial, Madrid, Siglo XXI, pp. 333.

CARRERAS, Albert, y TAFUNELL, Xavier (2003): Historia económica de la España Contemporánea, Barcelona, Crítica.

CATALAN, Jordi (1995): La economía española y la Segunda Guerra Mundial, Barcelona, Ariel.

-(2003): "La reconstrucción franquista y la experiencia de la Europa Occidental, 1934-1959", en BARCIELA, Carlos (ed.), Autarquía y mercado negro. El fracaso del primer franquismo, 1939-1959, Barcelona, Crítica, pp. 123-168.

CAZORLA, Antonio (2000): Las políticas de la victoria: la consolidación del Nuevo Estado franquista (1938-1953), Madrid, Marcial Pons.

COMÍN, Francisco (1988): Hacienda y economía en la España contemporánea (1800-1936), Madrid, Instituto de Estudios Fiscales, 2 vols.

-(1994): “La economía española en el período de entreguerras (1919-1935)”, en NADAL, Jordi; CARRERAS, Albert, y SUDRIÀ Carles (coords.), La economía española en el siglo XX. Una perspectiva histórica, Barcelona, Ariel, pp. 105-149.

-(1996): Historia de la Hacienda pública, II, España (1808- 1995), Barcelona, Crítica.

-(2002): "El período de entreguerras", en COMÍN, Francisco; HERNÁNDEZ, Mau-

ro, y LLOPIS, Enrique (eds.), Historia económica de España, siglos X-XX, Barcelona, Crítica, pp. 285-330.

DENINSON, Edward. F. (1952): “Distribution of National Income: Pattern of Income Shares since 1929", Survey of Current Business, 32, 6, pp. 16-23.

ERDOZAIN, Pilar (2000): “Perspectiva demográfica de la sociedad rural en la década de los noventa", Historia Agraria, 22, pp. 57-77.

ESPINA, Álvaro (1990): Empleo, democracia y relaciones industriales en España, Madrid, Ministerio de Trabajo y Seguridad Social. 
FOESSA (Fomento de Estudios Fiscales y de Sociología Aplicada) (1975): Estudios sociológicos sobre la situación social de España, Madrid, Fundación FOESSA, D. L.

FONTANA, Josep, y NADAL, Jordi (1980): “España 1914-1970”, en CIPOLLA, Carlo M. (ed.), Historia económica de la Europa contemporánea, vol. 6.2., Barcelona, Ariel, pp. 95-163.

GALBRAITH, John K. (1993): Historia de la economía, Barcelona, Ariel Sociedad Económica.

GALOR, Odded, y ZEIRA, Joseph (1993): “Income Distribution and Macroeconomics", Review of Economic Studies, 60, pp. 35-52.

GOLLIN, Douglas (2002): "Getting Income Shares Right", Journal of Political Economy, 110,2 , pp. 458-474.

INSTITUTO DE ESTUDIOS FISCALES (1969): La Contabilidad Nacional de España. Años 1954 a 1964, Madrid, Ministerio de Hacienda.

KEYNES, John M. (1939): "Relative movements of real wages and output", Economic Journal, 49, 143, pp. 34-51.

KRAVIS, Irving B. (1968): "Income distribution. I functional shares", en SILL, David L. (ed.), International encyclopedia of the social sciences, New York, Mac Millan, pp. 132-145.

KRUEGER, Alan B. (1999): “Measuring labour's share”, NBER, Working Paper, 413.

KUZNETS, Simon (1959): "Quantitative aspects of the economic growth of nations", Economic Development and Cultural Change, VII, 3, part. II, pp. 389-384.

MALUQUER DE MOTES, Jordi (1989): “Precios, salarios y beneficios: la distribución funcional de la renta", en CARRERAS, Albert (ed.), Estadísticas históricas de los siglos XIX y XX, Fundación del Banco Exterior, Madrid.

-(1994): “De la crisis colonial a la guerra europea; veinte años de economía española", en NADAL, Jordi, CARRERAS, Albert, y SUDRIÀ, Carles (coords.), La economía española en el siglo XX. Una perspectiva histórica, Barcelona, Ariel, $5^{\mathbf{a}}$ edición.

MARSHALL, Alfred (1963 [1890]): Principios de economía, México, Fondo de Cultura Económica.

MILL, John S. (1951 [1848]): Principles of Political Economy. Traducción castellana: Principios de Economía Política, México, FCE.

MIR CURCÓ, Conxita (ed.) (2002): La represión bajo el franquismo, Madrid, Asociación de Historia Contemporánea.

MOLINERO, Carme (1998): “Mujer, franquismo, fascismo. La clausura forzada en un mundo pequeño", Estudios de Historia Social, 30, pp. 97-117.

MOLINERO, Carme y YSÀS, Pere (1985): Patria, justicia y pan. Nivells de vida i condicions de treball a Catalunya 1939-1951, Barcelona, Edicions de la Magrana.

-(1998): Productores disciplinados y minorías subversivas. Clase obrera y conflictividad laboral en la España franquista, Madrid, Siglo XXI.

NICOLAU, Roser (1989): "La población", en CARRERAS, Albert (ed.), Estadísticas históricas de España de los siglos XIX y XX, Madrid, Fundación del Banco Exterior, pp. 49-90. 
PALAFOX, Jordi (1991): Atraso económico y democracia, Barcelona, Crítica.

PÉREZ-FUENTES, Pilar (1995): “El trabajo de las mujeres en la España de los siglos XIX y XX. Consideraciones metodológicas", Arenal, 2, 2, pp. 219-245.

PRADOS ARRARTE, Jesús (1972): La distribución de la renta nacional; salarios, intereses, rentas y beneficios, Madrid, Guadiana.

PRADOS DE LA ESCOSURA, Leandro (2003): El progreso económico de España (18502000), Madrid, Fundación BBVA.

PRADOS DE LA ESCOSURA, Leandro, y ROSÉS, Joan R. (2003): “Wages and labour income in history: A Survey", Working Paper 03-10, Economic History and Institutions, Series 06, Madrid, Universidad Carlos III.

PRO RUIZ, Juan (1995): “Ocultación de la riqueza rústica en España (1870-1936); acerca de la fiabilidad de las estadísticas sobre la propiedad y uso de la tierra", Revista de Historia Económica, XIII, 1, pp. 89-114.

RICARDO, David (1953 [1817]): Principles of Political Economy and Taxation, Cambridge, Cambridge University Press.

RODRIK, Daniel (1999): “Democracies pay higher wages", Quarterly Journal of Economics, 114, 3, pp. 707-738.

ROLDÁN, Santiago, y GARCÍA DELGADO, José L. (1973): La formación de la sociedad capitalista en España, 1914-1920, 2 Vols., Madrid, CECA.

SÁNCHEZ, Glicerio, y TASCÓN, Julio (eds.) (2003): Los empresarios de Franco. Política y economía en España, 1936-1957, Barcelona, Crítica.

SARASÚA, Carmen (2000): “El análisis histórico del trabajo agrario: cuestiones recientes", Historia Agraria, 22, pp. 79-96.

SARASÚA, Carmen, y GÁLVEZ, Lina (eds.) (2003): ¿Privilegios o eficiencia? Mujeres y hombres en los mercados de trabajo, San Vicente de Raspeig, Publicaciones de la Universidad de Alicante.

SILVESTRE, Javier (2003): Migraciones interiores y mercado de trabajo en España, 18771936, tesis doctoral inédita, Universidad de Zaragoza.

-(2005): "El grado de discriminación salarial de las mujeres en España, 1930: una primera aproximación", Investigaciones de Historia Económica, 2, pp. 105-144.

SMITH, Adam (1987 [1776]): The Wealth of Nations. Traducción castellana: Investigación sobre la naturaleza y causas de la riqueza de las naciones, Vilassar de Mar, Oikos-Tau, 2 volúmenes.

SOLOW, Robert M. (1958): "A sceptical note on the constancy of relative shares", The American Economic Review, 48, 4, pp. 618-631.

SOTO CARMONA, Álvaro (1989): El trabajo industrial en la España contemporánea, 1874-1936, Madrid, Anthropos.

SUDRIÀ, Carles (1990): “Los beneficios de España durante la gran guerra. Una aproximación a la balanza de pagos española, 1914-1920", Revista de Historia Económica, VIII, 2, pp. 363-395.

TAFUNELL, Xavier (1996): Los beneficios empresariales en España 1880-1981: Elaboración de una serie anual, Fundación Empresa Pública, documento de trabajo 9.601. 
-(1998): “Los beneficios empresariales en España 1880-1981. Estimación de un índice anual del excedente de la gran empresa", Revista de Historia Económica, XVI, 3, pp. 707-746.

-(2000): “La rentabilidad financiera de la empresa española 1880-1981: una estimación en perspectiva sectorial", Revista de Historia Industrial, 18, pp. 71-111.

VAN ZANDEN, Jan L. (1995): “Tracing the beginning of the Kuznets' curve: Western Europe during the early modern period", The Economic History Review, 48, 4, pp. 643-664.

VILAR, Margarita (2004a): Mercado de trabajo y crecimiento económico en España (19081963): una nueva interpretación del primer franquismo, tesis doctoral inédita, Universidad de Barcelona.

-(2004b): “La ruptura posbélica a través del comportamiento de los salarios industriales: nueva evidencia cuantitativa (1908-1963)", Revista de Historia Industrial, 25, pp. 81-126.

-(2006): "Estrategias de supervivencia de las familias trabajadoras en el marco laboral hostil de la posguerra civil española (1939-1958)", Sociología del Trabajo, 56, pp. 119-163.

WILLIAMSON, Jeffrey G., y LINDERT, Peter H. (1980): American Inequality: A Macroeconomic History, New York, New York University Press. 
APÉNDICE 1

\begin{tabular}{|c|c|c|c|c|c|c|c|c|c|c|}
\hline & \multirow{2}{*}{$\begin{array}{c}\text { Salario } \\
(1) \\
\end{array}$} & \multirow{2}{*}{$\begin{array}{c}\text { Empleo } \\
(2) \\
\end{array}$} & \multicolumn{2}{|c|}{ Masa salarial (3) } & \multirow{2}{*}{$\begin{array}{c}\text { Beneficios } \\
(4) \\
\end{array}$} & \multicolumn{2}{|c|}{ Masa salarial /Beneficios } & \multirow{2}{*}{$\begin{array}{l}\text { PIB } \\
(5)\end{array}$} & \multicolumn{2}{|c|}{ Masa salarial /PIB } \\
\hline & & & 300 (a) & $300-375(b)$ & & Ratio (3a/4) & Ratio (3b/4) & & Ratio (3a/5) & Ratio (3b/5) \\
\hline 1914 & 3,14 & 1.295 .240 & 1.220 .115 .806 & 1.220 .115 .806 & 278.766 .000 & 4,38 & 4,38 & 3.968 .000 .000 & 0,31 & 0,31 \\
\hline 1915 & 3,11 & 1.325 .770 & 1.236 .943 .041 & 1.236 .943 .041 & 366.680 .000 & 3,37 & 3,37 & 4.213 .000 .000 & 0,29 & 0,29 \\
\hline 1916 & 3,15 & 1.357 .801 & 1.283 .121 .703 & 1.283 .121 .703 & 513.086 .000 & 2,50 & 2,50 & 5.221 .000 .000 & 0,25 & 0,25 \\
\hline 1917 & 3,87 & 1.390 .351 & 1.614.197.282 & 1.614.197.282 & 624.171 .000 & 2,59 & 2,59 & 5.735 .000 .000 & 0,28 & 0,28 \\
\hline 1918 & 3,81 & 1.423 .596 & 1.627.170.147 & 1.627.170.147 & 714.869 .000 & 2,28 & 2,28 & 6.871 .000 .000 & 0,24 & 0,24 \\
\hline 1919 & 4,79 & 1.458 .349 & 2.095.647.522 & 2.095 .647 .522 & 684.748 .000 & 3,06 & 3,06 & 6.897 .000 .000 & 0,30 & 0,30 \\
\hline 1920 & 6,33 & 1.493 .790 & 2.836.707.775 & 2.836.707.775 & 662.079 .000 & 4,28 & 4,28 & 8.610 .000 .000 & 0,33 & 0,33 \\
\hline 1921 & 6,61 & 1.529 .023 & 3.032.052.723 & 3.032 .052 .723 & 592.391 .000 & 5,12 & 5,12 & 7.792 .000 .000 & 0,39 & 0,39 \\
\hline 1922 & 6,56 & 1.565 .886 & 3.081 .664 .592 & 3.081 .664 .592 & 614.657 .000 & 5,01 & 5,01 & 7.779 .000 .000 & 0,40 & 0,40 \\
\hline 1923 & 6,78 & 1.603 .961 & 3.262 .457 .244 & 3.262 .457 .244 & 641.641 .000 & 5,08 & 5,08 & 8.332 .000 .000 & 0,39 & 0,39 \\
\hline 1924 & 6,89 & 1.642 .404 & 3.394 .849 .804 & 3.394.849.804 & 705.260 .000 & 4,81 & 4,81 & 9.121 .000 .000 & 0,37 & 0,37 \\
\hline 1925 & 7,03 & 1.735 .648 & 3.660 .480 .941 & 3.660 .480 .941 & 698.983 .000 & 5,24 & 5,24 & 9.397 .000 .000 & 0,39 & 0,39 \\
\hline 1926 & 7,23 & 1.778 .123 & 3.856.748.704 & 3.856 .748 .704 & 787.481 .000 & 4,90 & 4,90 & 9.689 .000 .000 & 0,40 & 0,40 \\
\hline 1927 & 7,14 & 1.821 .097 & 3.900 .790 .844 & 3.900 .790 .844 & 744.986 .000 & 5,24 & 5,24 & 10.315 .000 .000 & 0,38 & 0,38 \\
\hline 1928 & 7,34 & 1.865 .420 & 4.107.655.669 & 4.107.655.669 & 869.499 .000 & 4,72 & 4,72 & 10.585 .000 .000 & 0,39 & 0,39 \\
\hline 1929 & 7,25 & 1.910 .775 & 4.155.935.972 & 4.155.935.972 & 951.112 .000 & 4,37 & 4,37 & 11.028 .000 .000 & 0,38 & 0,38 \\
\hline 1930 & 7,23 & 1.957 .491 & 4.245 .798 .593 & 4.245 .798 .593 & 972.557 .000 & 4,37 & 4,37 & 10.898 .000 .000 & 0,39 & 0,39 \\
\hline 1931 & 7,60 & 2.004 .298 & 4.569.798.950 & 4.569.798.950 & 758.234 .000 & 6,03 & 6,03 & 9.629 .000 .000 & 0,47 & 0,47 \\
\hline 1932 & 8,22 & 2.053 .348 & 5.063 .555 .064 & 5.063 .555 .064 & 739.976 .000 & 6,84 & 6,84 & 9.294 .000 .000 & 0,54 & 0,54 \\
\hline 1933 & 8,84 & 2.104 .188 & 5.580 .307 .693 & 5.580 .307 .693 & 689.951 .000 & 8,09 & 8,09 & 9.300 .000 .000 & 0,60 & 0,60 \\
\hline 1934 & 9,46 & 2.154 .601 & 6.114 .756 .415 & 6.114 .756 .415 & 717.123 .000 & 8,53 & 8,53 & 9.541 .000 .000 & 0,64 & 0,64 \\
\hline 1935 & 10,08 & 2.189 .680 & 6.621 .592 .173 & 6.621 .592 .173 & 808.942 .000 & 8,19 & 8,19 & 9.928 .000 .000 & 0,67 & 0,67 \\
\hline 1940 & n.d. & 1.726 .171 & --- & --- & 1.189 .343 .000 & --- & --- & 11.748 .000 .000 & --- & --- \\
\hline 1941 & n.d. & 1.783 .209 & --- & --- & 1.354 .344 .000 & --- & --- & 12.550 .000 .000 & --- & --- \\
\hline 1942 & n.d. & 1.843 .393 & --- & --- & 1.576 .784 .000 & --- & --- & 16.328 .000 .000 & --- & --- \\
\hline 1943 & 15,70 & 1.904 .396 & 8.969.703.770 & 11.212.129.712 & 1.868 .007 .000 & 4,80 & 6,00 & 16.577 .000 .000 & 0,54 & 0,68 \\
\hline 1944 & 15,50 & 1.967 .802 & 9.150 .281 .325 & 11.437 .851 .656 & 2.286 .711 .000 & 4,00 & 5,00 & 19.144 .000 .000 & 0,48 & 0,60 \\
\hline 1945 & 15,30 & 2.005 .446 & 9.204 .994 .930 & 11.506.243.662 & 2.938 .257 .000 & 3,13 & 3,92 & 19.948 .000 .000 & 0,46 & 0,58 \\
\hline 1946 & 19,33 & 2.073 .217 & 12.022 .585 .329 & 15.028 .231 .661 & 3.398 .702 .000 & 3,54 & 4,42 & 26.561 .000 .000 & 0,45 & 0,57 \\
\hline 1947 & 20,47 & 2.142 .363 & 13.156 .248 .803 & 16.445 .311 .004 & 4.146 .498 .000 & 3,17 & 3,97 & 32.130 .000 .000 & 0,41 & 0,51 \\
\hline 1948 & 21,94 & 2.213 .447 & 14.568 .910 .763 & 18.211.138.454 & 4.744 .102 .000 & 3,07 & 3,84 & 37.852 .000 .000 & 0,38 & 0,48 \\
\hline 1949 & 21,75 & 2.287 .669 & 14.927 .042 .295 & 18.658 .802 .869 & 5.203 .875 .000 & 2,87 & 3,59 & 35.083 .000 .000 & 0,43 & 0,53 \\
\hline
\end{tabular}


APÉNDICE 1 (continuación)

\begin{tabular}{|c|c|c|c|c|c|c|c|c|c|c|}
\hline & \multirow{2}{*}{$\begin{array}{c}\text { Salario } \\
(1)\end{array}$} & \multirow{2}{*}{$\begin{array}{c}\text { Empleo } \\
\text { (2) }\end{array}$} & \multicolumn{2}{|c|}{ Masa salarial (3) } & \multirow{2}{*}{$\begin{array}{c}\text { Beneficios } \\
(4)\end{array}$} & \multicolumn{2}{|c|}{ Masa salarial /Beneficios } & \multirow{2}{*}{$\begin{array}{l}\text { PIB } \\
\text { (5) }\end{array}$} & \multicolumn{2}{|c|}{ Masa salarial /PIB } \\
\hline & & & $300(a)$ & $300-375(b)$ & & Ratio (3a/4) & Ratio (3b/4) & & Ratio (3a/5) & Ratio (3b/5) \\
\hline 1950 & 25,23 & 2.363 .426 & 17.888 .774 .974 & 22.360 .968 .718 & 6.447 .919 .000 & 2,77 & 3,47 & 46.088 .000 .000 & 0,39 & 0,49 \\
\hline 1951 & 25,78 & 2.377 .336 & 18.386.317.132 & 22.982 .896 .415 & 7.975 .914 .000 & 2,31 & 2,88 & 65.523 .000 .000 & 0,28 & 0,35 \\
\hline 1952 & 25,77 & 2.390 .680 & 18.482.349.425 & 23.102.936.781 & 8.629 .506 .000 & 2,14 & 2,68 & 73.889 .000 .000 & 0,25 & 0,31 \\
\hline 1953 & 26,20 & 2.403 .779 & 18.893.699.028 & 23.617.123.785 & 10.822.753.000 & 1,75 & 2,18 & 85.224 .000 .000 & 0,22 & 0,28 \\
\hline 1954 & 28,09 & 2.417 .197 & 20.369.717.385 & 25.462 .146 .731 & 12.545 .712 .000 & 1,62 & 2,03 & 100.284 .000 .000 & 0,20 & 0,25 \\
\hline 1955 & 28,30 & 2.389 .336 & 20.285 .466 .591 & 25.356 .833 .239 & 16.650 .020 .000 & 1,22 & 1,52 & 112.338 .000 .000 & 0,18 & 0,23 \\
\hline 1956 & 45,49 & 2.448 .689 & 33.417 .264 .209 & 41.771 .580 .262 & 18.946.318.000 & 1,76 & 2,20 & 142.032 .000 .000 & 0,24 & 0,29 \\
\hline 1957 & 47,44 & 2.539 .704 & 36.145 .063 .816 & 45.181 .329 .770 & 23.647 .810 .000 & 1,53 & 1,91 & 167.097.000.000 & 0,22 & 0,27 \\
\hline 1958 & 48,46 & 2.639 .787 & 38.377 .216 .982 & 47.971 .521 .227 & 32.509 .198 .000 & 1,18 & 1,48 & 196.859 .000 .000 & 0,19 & 0,24 \\
\hline 1959 & 48,85 & 2.635 .457 & 38.622 .615 .542 & 48.278 .269 .427 & 32.566 .596 .000 & 1,19 & 1,48 & 200.976 .000 .000 & 0,19 & 0,24 \\
\hline
\end{tabular}

Fuentes:

1) Salario diario nominal masculino en la industria y la construcción en Vilar (2004b), cuadro A.2.1, pp. 124-125. Los datos salariales entre 1932 y 1934 han sido obtenidos por interpolación.

(2) Empleo masculino en la industria y la construcción a partir de Nicolau (1989) y Prados (2003).

(3) Masa salarial masculina en la industria y la construcción considerando que el número de jornadas trabajadas asciende a 300 antes y después de la Guerra Civil (a) o considerando que en la posguerra aumentó por término medio un 25 por 100 el tiempo trabajado (b). Para más detalle véase texto.

(4) Beneficios empresariales en términos nominales en Tafunell (1996), p. 44

(5) PIB nominal a coste de factores en la industria y la construcción en Prados (2003), cuadro A.11.1, p. 572. 